\title{
Daily Precipitation Fields Modeling across the Great Lakes Region (Canada) by Using the CFSR Reanalysis $\mathscr{a}$
}

\author{
Dikra Khedhaouiria, Alain Mailhot, And Anne-Catherine Favre ${ }^{\mathrm{a}}$ \\ Institut National de la Recherche Scientifique, Centre Eau Terre Environnement (INRS-ETE), Québec City, Québec, Canada
}

(Manuscript received 19 January 2018, in final form 16 July 2018)

\begin{abstract}
Reanalyses, generated by numerical weather prediction methods assimilating past observations, provide consistent and continuous meteorological fields for a specific period. In regard to precipitation, reanalyses cannot be used as a climate proxy of the observed precipitation, as biases and scale mismatches exist between the datasets. In the present study, a stochastic model output statistics (SMOS) approach combined with metaGaussian spatiotemporal random fields was employed to cope with these caveats. The SMOS is based on the generalized linear model (GLM) and the vector generalized linear model (VGLM) frameworks to model the precipitation occurrence and intensity, respectively. Both models use the Climate Forecast System Reanalysis (CFSR) precipitation as covariate and were locally calibrated at 173 sites across the Great Lakes region. Combined with meta-Gaussian random fields, the GLM and VGLM models allowed for the generation of spatially coherent daily precipitation fields across the region. The results indicated that the approach corrected systematic biases and provided an accurate spatiotemporal structure of daily precipitation. Performances of selected precipitation indicators from the joint Commission for Climatology (CCl)/CLIVAR/ JCOMM Expert Team on Climate Change Detection and Indices (ETCCDI) were good and were systematically improved when compared to CFSR.
\end{abstract}

\section{Introduction}

Adequate spatiotemporal characterization of precipitation fields is essential (Serinaldi and Kilsby 2014). Hydrological modeling over large areas is one of the most important applications for which spatially and temporally continuous precipitation inputs are ideally required (Lamb et al. 2016). Continuous input series improve our ability to simulate infiltration, runoff, and all major hydrological processes and provide better risk assessments than, for example, using the classical design storm approach (Lamb et al. 2016; Li et al. 2014).

Available gridded precipitation datasets are mainly based on the interpolation of available station records

\footnotetext{
Supplemental information related to this paper is available at the Journals Online website: https://doi.org/10.1175/JAMC-D-180019.s1.

${ }^{a}$ Current affiliation: Université Grenobles Alpes, CNRS, IRD, Grenoble INP, IGE, F-38000 Grenoble, France.
}

Corresponding author: Dikra Khedhaouiria,dikra.khedhaouiria@ ete.inrs.ca
(Hopkinson et al. 2011), on a combination of satellite estimates and station records (Huffman et al. 1995), or on dynamically based models [e.g., reanalyses; see Table 1 in Beck et al. (2017) for a nonexhaustive list of available precipitation datasets]. Each of these datasets has its advantages and drawbacks. Thus, the quality of interpolated datasets depends both on the interpolation method and on the density of stations, and it is also well known that they underestimate extreme precipitation (Way et al. 2017; Contractor et al. 2015; Gervais et al. 2014b; Hofstra et al. 2010). Therefore, regions where available records cover relatively short periods of time, and where spatial coverage remains sparse (e.g., northern regions), are prone to large interpolation errors (Way et al. 2017; Contractor et al. 2015; Gervais et al. 2014b; Hofstra et al. 2010). Satellite-based precipitation datasets cover only short time periods, have issues with the estimation of certain kinds of precipitation (e.g., shallow precipitation and snowfall; Behrangi et al. 2014), and underestimate extremes (Contractor et al. 2015; Gervais et al. 2014a; Sun et al. 2010). Dynamically based datasets, such as reanalyses, differ from interpolated and satellite products. Reanalyses assimilate several past observations over a given period (Bengtsson and Shukla 1988) and provide 
valuable (to some extent) spatiotemporal information for several physical fields. However, reanalyses are subject to systematic and random errors (due, for example, to the parameterization of physical processes occurring at the subgrid scale; Lorente-Plazas and Hacker 2017) that could prevent their use in impact studies or hydrological modeling.

Therefore, it is essential to post-process the precipitation from reanalyses with approaches that reproduce spatial and temporal structures. The objective of this study is to correct and to downscale gridded daily Climate Forecast System Reanalysis (CFSR) precipitation. Stochastic spatiotemporal post-processing models were developed for this purpose. Different statistical approaches have been proposed in the literature to enable the spatiotemporal modeling of daily precipitation. Haberlandt et al. (2011) proposed the classification of these statistical approaches into five groups: 1) time series models that generate long time series using a generalized linear model (GLM) or a chain-dependent process (Bardossy and Plate 1992), 2) alternating renewal processes based on the analyses of wet- and dry-spell events (Pegram and Clothier 2001), 3) point processes that provide probabilistic arrival times of precipitation at the subdaily scale (Onof et al. 2000), 4) disaggregation models based on the scaling properties of precipitation that temporally and spatially disaggregate precipitation (Lombardo et al. 2017), and 5) resampling techniques that do not require distribution assumptions of the random process and are based on sampling of observed values (Buishand and Brandsma 2001). Haberlandt et al. (2011) and Wheater et al. (2005) proposed an extensive review of these approaches. Among these techniques, the time series models combined with meta-Gaussian spatiotemporal random fields appeared as the most efficient at post-processing CFSR precipitation while providing at-site and spatially consistent daily precipitation series (Serinaldi and Kilsby 2014). The daily precipitation mixed distribution with both its discrete and continuous components led to combinations of two time series models for modeling considerations: GLMs were applied to model the precipitation occurrences and vector generalized linear models (VGLMs) to model the intensity on wet days, both using daily CFSR precipitation series as a predictor. Binomial and two-parameter gamma distributions were selected to model, respectively, the discrete component (wet and dry states) and the continuous component (intensities on wet days) of the mixed daily precipitation distribution. Since random series generated from the gamma distributions lack the appropriate spatiotemporal structure of observed series (Khedhaouiria et al. 2018), the meta-Gaussian spatiotemporal latent field was considered to address this issue (Serinaldi and Kilsby 2014).
Very few studies have developed processing models based on reanalysis precipitation. Eum et al. (2017) have directly used reanalysis precipitation for downscaling purposes. However, stochastic simulations of the daily precipitation generally used several large-scale predictors exogenous to the precipitation (Asong et al. 2016; Vaittinada Ayar et al. 2016). Asong et al. (2016) applied a multisite GLM framework with several covariates from the NCEP-NCAR Reanalysis 1 (Kalnay et al. 1996) across the Canadian prairies to generate stochastic simulations of daily precipitation. However, while these authors adopted a multisite approach, they did not aim at providing spatially consistent daily precipitation fields. Serinaldi and Kilsby (2014) developed similar statistical tools to those of the present study across the Danube basin with the sea level pressure (SLP) from the NCEP-NCAR Reanalysis 1 as a predictor. Besides using CFSR precipitation as a predictor, one major difference in the present paper with respect to Serinaldi and Kilsby's (2014) study is that local-scale daily precipitation is considered here whereas Serinaldi and Kilsby (2014) simulated precipitation on a $25-\mathrm{km}$ resolution grid. These authors modeled the precipitation intensity using the generalized Pareto and Weibull distributions and showed the overall good performance of their approach for different temporal and spatial scales. Similar approaches were applied by Baxevani and Lennartsson (2015) to 12 stations in Sweden with one latent Gaussian field modeling both the occurrence and intensity processes, without considering, however, any physical large-scale covariates. Baxevani and Lennartsson (2015) highlighted the advantages of their approach to represent some precipitation properties but underlined the potential of the climate variables as covariates to further improve the realism of the simulated precipitation fields. Bennett et al. (2018) also demonstrated the relevance of a latent Gaussian field to model precipitation occurrence and intensity jointly across 22 stations in South Australia while also providing an evaluation framework for daily precipitation fields. Khedhaouiria et al. (2018) investigated a similar at-site post-processing approach for CFSR precipitation across Canada. The authors showed the potential of the downscaled reanalysis to represent selected precipitation characteristics. Khedhaouiria et al. (2018) also highlighted the need to consider the spatial structure and temporal persistence to ensure consistency in the daily precipitation field. The main contributions of the proposed approach are, first, to use precipitation from the reanalysis as a covariate, which results in a simple approach to generate local-scale precipitation that can be readily implemented. Second, it also enables the implementation of one latent field to ensure consistent 
daily precipitation fields across geographic regions encompassing interesting climatic features (snowbelts around the Great Lakes; Lucas-Picher et al. 2017). In this study, we developed a post-processing model whose objective is to take advantage of the post-processed information provided by the reanalysis to stochastically generate precipitation series at sites. Stochastic model output statistics (SMOS) combined with a metaGaussian random field approach was therefore first applied at sites where observations were available to assess the performance of this approach. Regional mapping (e.g., kriging methods) based on this approach could be used to generate various statistics at ungauged sites.

The present paper is structured as follows. Available datasets are presented in section 2, while the stochastic spatiotemporal post-processing framework is described in section 3. Section 4 presents the evaluation approach while results are summarized in section 5. Finally, the conclusions are given in section 6 .

\section{Datasets}

Observed daily precipitation series at 857 stations, covering the Great Lakes region, as defined by Plummer et al. (2006), were initially considered. Precipitation in this region is highly influenced by the lakes with high spatial variability in annual total precipitation (Fig. 1). Forty-one of these stations belong to the secondgeneration Adjusted Precipitation for Canada dataset (APC2; Mekis and Vincent 2011; Environment and Climate Change Canada 2013). APC2 series were adjusted to account for wind undercatch, evaporation, and funnel wetting, with regard to rain, and improved snow density assessment (Mekis and Vincent 2011; Devine and Mekis 2008). The remaining stations (816) also provided by Environment and Climate Change Canada did not undergo any preliminary adjustments to correct possible nonhomogeneities. Some of these stations (857) were considered after a preliminary quality control process described in the next paragraph.

The following criteria were applied to quality control observed series: 1) each year was required to have fewer than $10 \%$ missing daily values to be considered as a valid year and 2) stations needed to have at least 20 valid years during the study period (1979-2009) and more than five consecutive valid years. This last criterion was imposed to avoid datasets with sparse valid years.

Importantly, some stations may include recording inconsistencies due to factors such as changes in recording equipment, changes in the definition and measurements of precipitation traces (Mekis 2005), missing values, choices of time windows to record daily precipitation (Hopkinson et al. 2011), and other site disturbances

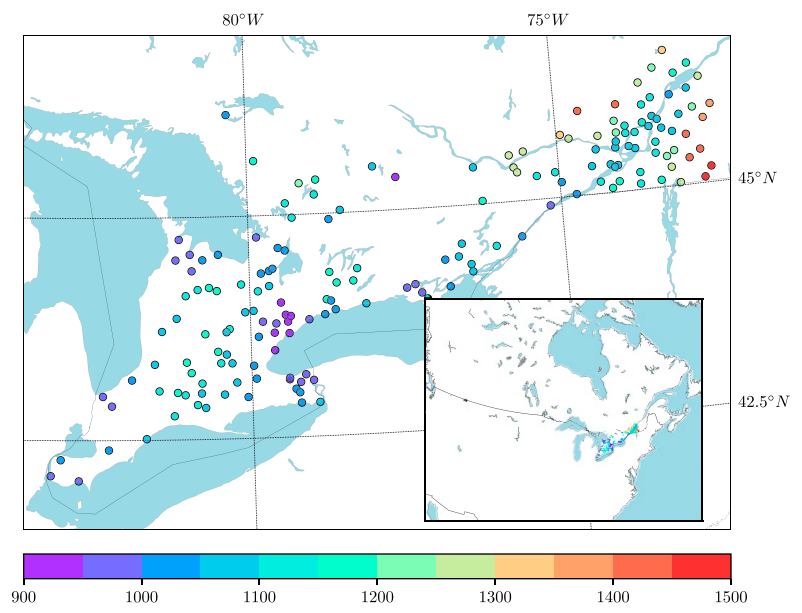

FIG. 1. Rainfall network used across the Great Lakes region with the corresponding recorded mean annual precipitation $(\mathrm{mm})$ over the 1979-2009 period.

(Beaulieu et al. 2008). To further scrutinize the data, especially at stations that were not part of the APC2 dataset, the statistical homogeneity of annual precipitation series was also assessed with the Wijngaard et al. (2003) approach. On the basis of four statistical tests [standard normal homogeneity test, Buishand range test, Von Neumann ratio test, and Pettitt test; see Wijngaard et al. (2003) and references therein], the series were classified as "useful," "doubtful," or "suspect." In the following, only stations with useful series were selected, that is, when at least three of the tests do not reject the null hypothesis that the temporal series are identically distributed at the $99 \%$ confidence level. After applying this procedure, a total of 173 valid precipitation series were identified and further considered for analysis. Figure 1 presents a map of the selected stations. Distances between pairs of stations range from 1 to $950 \mathrm{~km}$.

The CFSR was produced by the National Centers for Environmental Prediction (NCEP) with the Coupled Forecast System (CFS) model and covers the 1979-2009 period (Saha et al. 2010). This model simulates the past state of the ocean and atmosphere at a horizontal resolution of $0.312^{\circ}$ latitude $\times 0.312^{\circ}$ longitude $(\sim 38 \mathrm{~km}$ at $\left.45^{\circ} \mathrm{N}\right)$, by assimilating quality-controlled observations. CFSR also includes in the land model two gridded precipitation products: 1) the pentad dataset of CMAP and 2) the CPC unified global daily gauge analysis [see Saha et al. (2010) and references therein]. CFSR differs from other reanalyses in that it uses a coupled atmosphereocean-sea ice-land model (Bromwich et al. 2011), assimilates satellite radiances during the entire period, and includes the time evolution of $\mathrm{CO}_{2}$ concentrations [for more details see Mesinger et al. (2006)]. The CFSR hourly precipitation amounts were aggregated to daily values. 


\section{Methodology}

The proposed stochastic spatiotemporal postprocessing approach proceeds in four steps as illustrated in Fig. 2. First, daily precipitation distributions were modeled. The mixed discrete and continuous distribution of precipitation led us to consider separately the occurrence of wet and dry days (a wet day is defined as a day with more than $1 \mathrm{~mm}$ of precipitation; Dai 2006; Schmidli et al. 2006; Sun et al. 2006, among others) and the precipitation intensity on wet days (Neykov et al. 2014; Chandler and Wheater 2002; Coe and Stern 1982). The marginal distributions of precipitation occurrence and intensity were modeled within the GLM/VGLM framework (Yee and Wild 1996), both using CFSR precipitation as a predictor. These distributions were built independently at each site with the corresponding CFSR grid cell (section 3a). The main goal here was to provide precipitation distributions for each day, conditional on CFSR precipitation for the same day (step 2 in Fig. 2). The third steps involved the implementation of the latent meta-Gaussian fields to generate spatially and temporally dependent uniform random fields (Fig. 2, step $3)$. The previous were combined with the GLM/VGLM models to generate daily precipitation series with a consistent spatiotemporal structure (Fig. 2, step 4). The models building the post-processing approach at each step are described hereafter.

\section{a. Occurrence and intensity modeling}

The marginal distribution of precipitation occurrence was modeled within a GLM framework using a binomial family function (Buishand et al. 2004; Stern and Coe 1984). In this logistic regression, the predictand was the recorded wet or dry state and the predictor was the log-transformed daily CFSR intensity $x_{i}$ (Chandler and Wheater 2002). To account for seasonality, sine and cosine functions were added. The conditional probability $p_{i}$ of a day $i$ being wet was therefore defined as

$$
\begin{aligned}
g\left(p_{i}\right)= & \log \left(\frac{p_{i}}{1-p_{i}}\right) \\
= & \alpha_{0}+\alpha_{1} \log \left(x_{i}+1\right)+\alpha_{2} \cos \left(\frac{2 \pi d}{T}\right) \\
& +\alpha_{3} \sin \left(\frac{2 \pi d}{T}\right),
\end{aligned}
$$

where $g($.$) denotes the logit function, d$ the ordinal day, and $T=365.25$ days (the average yearly period for cosine and sine functions accounting for leap years). The $\left\{\alpha_{k}\right\}_{k \in[0,3]}$ are the regression coefficients estimated by maximum likelihood (MLE) with an iteratively reweighted least squares (IRLS) procedure (Buishand et al. 2004).
The two-parameter gamma distribution was selected to model the marginal of the precipitation intensity for wet days. The parameterization using the shape $(\gamma>0)$ and mean $(\mu>0)$ parameters was chosen (McCullag and Nelder 1989). With this parameterization, the scale parameter is given by $\mu / \gamma$ and the variance by $\mu^{2} / \gamma$. The probability density function $f_{\mu, \gamma}$ is expressed as

$$
f_{\mu, \gamma}(z)=\frac{\gamma}{\mu \Gamma(\gamma)}\left(\frac{\gamma z}{\mu}\right)^{\gamma-1} e^{-\gamma z / \mu},
$$

where $\Gamma$ denotes the gamma function and $z>0$ the daily precipitation intensity. The daily local precipitation intensity distribution, conditional on CFSR precipitation, was defined within the VGLM framework (Yee and Wild 1996). VGLMs can be viewed as generalizations of GLMs that encompass the exponential distribution family and that enable for each distribution parameter to vary linearly according to several predictors (Yee 2016). Parameters $\mu_{i}$ and $\gamma_{i}$ of the gamma distribution on day $i$ were expressed as a function of the log-transformed CFSR daily intensity $x_{i}$. Seasonal post-processing terms (first-order harmonic regression) were also considered for the mean $\mu_{i}$. The resulting expressions can be written as

$$
\begin{aligned}
h\left(\mu_{i}\right)= & \eta_{0}+\eta_{1} \log \left(x_{i}+1\right)+\eta_{2} \cos \left(\frac{2 \pi d}{T}\right) \\
& +\eta_{3} \sin \left(\frac{2 \pi d}{T}\right), \\
h\left(\gamma_{i}\right)= & \beta_{0}+\beta_{1} \log \left(x_{i}+1\right),
\end{aligned}
$$

where $h($.$) is the log link function, T=365.25$ days, and $\left\{\eta_{k}\right\}_{k \in[0,3]}$ and $\left\{\beta_{k}\right\}_{k \in[0,1]}$ are the regression coefficients estimated using the MLE method [Yee 2016; Comprehensive R Archive Network (CRAN) R VGAM package]. Fitting the intensity model with precipitation values above a 1-mm threshold $(z>1 \mathrm{~mm})$ led to misfits for small intensities as the gamma distribution is defined on $x \in(0,+\infty)$ (Wong et al. 2014). Precipitation on wet days, ranging over $(1,+\infty)$, was therefore shifted by $-1 \mathrm{~mm}$, and the gamma distribution parameter was estimated using that series. The resulting distribution was then shifted back by $+1 \mathrm{~mm}$. Model selection is discussed in section 5 .

Combining the conditional probability of occurrence $p_{i}$ [Eq. (1)] and the cumulative distribution function (CDF) of the daily precipitation intensity $F_{\mu_{i}, \gamma_{i}}$ [from Eqs. (2) and (3)], the mixed CDF of the local precipitation on day $i$, denoted $Z_{i}$, can be written as (see Fig. 2, steps 1 and 2)

$$
\mathbb{P}\left(Z_{i} \leq z\right)=p_{i} F_{\mu_{i}, \gamma_{i}}(z)+\left(1-p_{i}\right)
$$




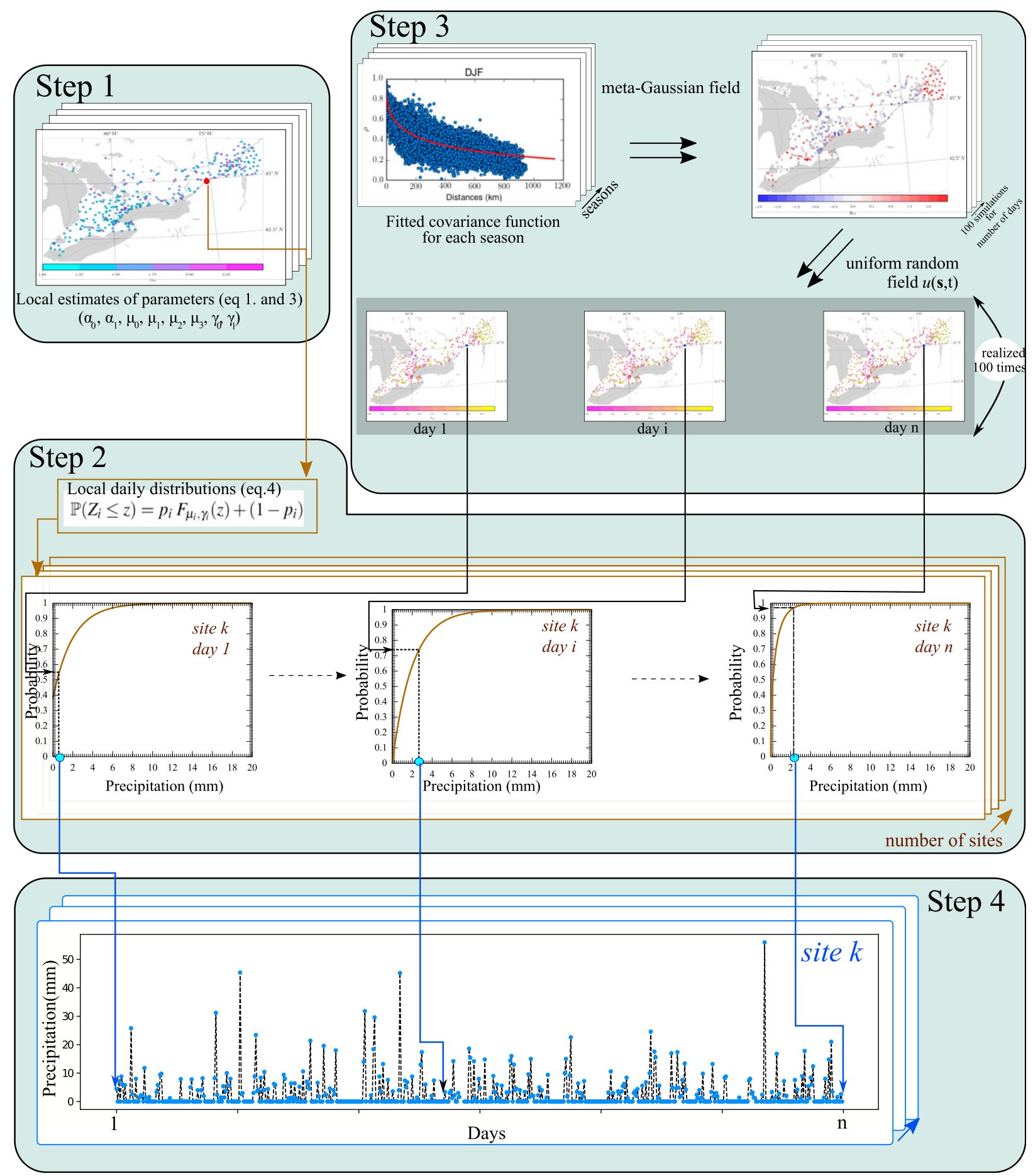

FIG. 2. Illustration of the different steps of the post-processing approach.

\section{b. Meta-Gaussian random field}

One meta-Gaussian random field was used to generate spatiotemporal uniform random fields with spatial and temporal structures similar to those of recorded daily precipitation. This parsimonious approach, developed by Serinaldi and Kilsby (2014), was used to model these structures using both the occurrence and intensity of the daily precipitation. 


\section{1) SPATiAl COMPONENT}

The modeling of the random process $Z(\mathbf{s}, t)$, where $\mathbf{s}$ and $t$ are, respectively, the position in a $d$-dimensional space $\mathbb{R}^{d}(d \geq 1)$ and the time, is based on a multivariate Gaussian framework. The process was then defined by its covariance function $C(\mathbf{s}, t)$ (Stein 1999). To enable the use of the theory of random field simulations, a covariance function of the daily precipitation must be specified and fitted to the empirical covariagram (the correlation between the pair of spatial observations varying in accordance with the distances; see step 3 in Fig. 2). For the sake of simplicity, the covariance function was assumed stationary and isotropic but with different covariances according to the season. The covariance is only a function of the distance between pairs of points $C(\mathbf{h})$, where $h=\left\|s_{i}-s_{j}\right\|_{i \neq j}$. Due to the skewness of the daily precipitation distribution, Kendall's nonparametric correlation coefficient $\tau_{k}$ was used instead of the Pearson coefficient to estimate the interstation correlation. Kendall's $\tau_{k}$ is also advantageous in that it can be directly linked to the Pearson coefficient of correlation $\rho_{s}$ with the following expression, $\rho_{s}=\sin \left(\tau_{k} \pi / 2\right)$ (Kendall 1962), and then can be applied in the random field simulations. Several parametric covariance functions were tested (Cressie and Huang 1999), and the one that best fit the empirical covariance, according to the weighted least squares criterion, was selected (section 5). Finally, 100 random field simulations were carried out with the CRAN R VGAM package (Schlather et al. 2017; see step 3 in Fig. 2).

\section{2) TEMPORAL COMPONENT}

The definition of a spatial covariance structure allows for the simulation of a random field but without taking into account the temporal autocorrelation. Following Serinaldi and Kilsby (2014), a lag-1 autocorrelation $\rho_{\Delta}$ was introduced to ensure temporal dependence in the random field by using the following expression (Podgórski and Wegener 2012):

$$
y(\mathbf{s}, t+1)=\rho_{\Delta} y(\mathbf{s}, t)+\sqrt{1-\rho_{\Delta}^{2}} z(\mathbf{s}),
$$

where $y$ is the spatiotemporal Gaussian random field and $z$ the spatial random field varying according to seasons [section $3 b(1)]$. As for the spatial analysis, the lag-1 temporal autocorrelations were first assessed using Kendall's $\tau_{k}$ and then linked to Pearson correlation coefficients. As the temporal autocorrelations, simulated by CFSR, were in agreement with the recorded values (not shown here), CFSR daily precipitation autocorrelations were used in the post-processing. This choice was guided by outside purposes, not developed in the present study, to simulate at sites without records. Finally, to generate simulations from the daily precipitation distribution [Eq. (4)], the Gaussian random field was transformed to spatiotemporal uniform fields using the expression $u(s, t)=\phi^{-1}[y(s, t)]$, where $\phi^{-1}$ is the inverse Gaussian cumulative distribution function (see steps 3 and 4 in Fig. 2).

\section{Evaluation framework of the post-processed series}

One hundred precipitation series, referred to hereafter as post-processed series, were randomly generated according to the methodology developed in the previous section (Fig. 2, step 4). Several characteristics of the post-processed series at different temporal and spatial scales were assessed within a cross-validation framework explained hereafter. First, the daily characteristics that define the occurrence, persistence, and intensity of the at-site daily precipitation were estimated. Then, annual and seasonal precipitation totals were investigated for selected climate indices (Table 1). Finally, spatial characteristics of the precipitation field were investigated through spatially averaged precipitation series [see section $4 \mathrm{~b}(2)$ ]. Table 2 summarizes all the indices and characteristics that were evaluated. The evaluation of the proposed methodology aimed to answer two questions: 1) Are the characteristics/indices of the observed series more adequately reproduced by the post-processed series than by the CFSR series? 2) Does the post-processed series provide good estimates when compared to the observations?

\section{a. Cross-validation framework}

The performance of the post-treatment was evaluated within a cross-validation framework. Daily time series at each site were split so that the last 10 years were used for validation, while the first years (at least 10 years) were used for calibration. The calibration period's length therefore depends on site but is minimally 10-yr long. Approximately $60 \%$ of the sites have 18 years or more for calibration periods. The distribution of the number of years used for the calibration period is presented in Fig. S1 in the online supplemental material. The GLM, VGLM, and the meta-Gaussian random field were all fitted on the calibration period and evaluated for both periods.

\section{b. Evaluation tools}

Following Bennett et al. (2018), an adaptation of the Comprehensive and Systematic Evaluation (CASE) framework was used to evaluate and compare the observed and post-processed series. The CASE framework allows comparisons of an ensemble of stochastic precipitation simulations to observations by classifying the 
TABLE 1. Precipitation indices from the ETCCDI list computed at the annual and seasonal time scales (Peterson et al. 2001).

\begin{tabular}{|c|c|c|c|}
\hline Climate index identifier & Name & Description & Unit \\
\hline \multicolumn{4}{|l|}{ Duration } \\
\hline CDD & Consecutive dry days & Annual max No. of consecutive dry days $(<1 \mathrm{~mm})$ & days \\
\hline CWD & Consecutive wet days & Annual max No. of consecutive wet days ( $\geq 1 \mathrm{~mm}$ ) & days \\
\hline \multicolumn{4}{|l|}{ Frequency } \\
\hline $\mathrm{R} 10 \mathrm{~mm}$ & No. of heavy precipitation days & Annual No. of days with precipitation $\geq 10 \mathrm{~mm}$ & - \\
\hline $\mathrm{R} 20 \mathrm{~mm}$ & No. of very heavy precipitation days & Annual No. of days with precipitation $\geq 20 \mathrm{~mm}$ & - \\
\hline \multicolumn{4}{|l|}{ Intensity } \\
\hline PRCPTOT & Total wet day precipitation & Annual total precipitation & $\mathrm{mm}$ \\
\hline Rx1day & Max 1-day precipitation & Annual max 1-day precipitation & $\mathrm{mm}$ \\
\hline Rx5day & Max 5-day precipitation & Annual max 5-day precipitation & $\mathrm{mm}$ \\
\hline $\mathrm{R} 95 \mathrm{p}$ & Very wet days & $\begin{array}{l}\text { Annual amount when daily precipitation is }>95 \text { th percentile } \\
\text { of the daily precipitation during the reference period }\end{array}$ & $\mathrm{mm}$ \\
\hline R99p & Extremely wet days & $\begin{array}{l}\text { Annual amount when daily precipitation is }>99 \text { th percentile } \\
\text { of the daily precipitation during the reference period }\end{array}$ & $\mathrm{mm}$ \\
\hline
\end{tabular}

performances into three categories: 1) good, if the observation lies within the simulation's $90 \%$ probability limits; 2) fair, if the observation lies within the simulation's $99.7 \%$ probability limits, assuming the uncertainty is normally distributed, or if the absolute relative difference between the observation and the averaged simulations is under 5\%; and 3) poor otherwise. An important advantage of the CASE approach is that it provides a unique and systematic framework for analyzing model performances for all indices and characteristics. Since the CASE framework allows for the comparison of single value to intervals, it was adapted, as illustrated in Fig. 3, to compare observed values to corresponding CFSR values. The good and fair categories were attributed to performances when the absolute relative differences between these two datasets were smaller than, respectively, $2.5 \%$ and $5 \%$ and poor otherwise. The following sections provide further details about the selected climate indices and how the CASE framework was adapted to allow for year-to-year assessment. The spatiotemporal evaluation of the postprocessed time series was also further developed.

\section{1) ANNUAL AND SEASONAL ASSESSMENT}

The at-site precipitation annual cycle is an important feature that must be well represented by the postprocessing approach. Monthly precipitation averaged over the two periods (calibration/validation) were

TABLE 2. Summary of the characteristics assessed at the corresponding temporal and spatial scales.

\begin{tabular}{|c|c|c|c|}
\hline Spatial scale & Time scale & Time series from which characteristics are derived & Characteristics to be assessed \\
\hline \multirow[t]{5}{*}{ At site } & \multirow[t]{4}{*}{ Climate } & Daily precipitation & $\begin{array}{l}\text { Mean, mean on wet days, std dev, } 95 \text { th percentile, } \\
\text { No. of wet days, and autocorrelation from lag } 1 \text { to } 3\end{array}$ \\
\hline & & $\begin{array}{l}\text { Durations of independent dry and wet events [a wet } \\
\text { event (dry) is followed and preceded by, at least, } \\
\text { one dry (wet) day] }\end{array}$ & $\begin{array}{l}\text { Frequency of occurrence of the dry and wet events } \\
\text { for various durations (1-5 days) }\end{array}$ \\
\hline & & Time series of occurrences of dry and wet days & Markov transition probabilities \\
\hline & & $\begin{array}{l}\text { Monthly amount averaged over the } 1979-2009 \text { period } \\
\text { from daily precipitation at each site (annual cycle) }\end{array}$ & Pearson correlation for the annual cycle \\
\hline & Annual & $\begin{array}{l}\text { Annual and seasonal series for selected ETDCCI } \\
\text { indices (see Table 1) }\end{array}$ & Index estimates per year and per year per season \\
\hline \multirow[t]{4}{*}{ Region } & \multirow[t]{3}{*}{ Climate } & Daily precipitation & Spatial correlation between pairs of sites \\
\hline & & Time series of occurrences of dry and wet days & $\begin{array}{l}\text { Proportion of days when the pair of sites are } \\
\text { simultaneously wet or dry }\end{array}$ \\
\hline & & $\begin{array}{l}\text { Monthly amount averaged over the } 1979-2009 \text { period } \\
\text { from the spatially averaged daily precipitation across } \\
\text { the region (one time series for the region with } \\
12 \text { values, each is a climate average for a month) }\end{array}$ & Pearson correlation on the annual cycle \\
\hline & Annual & $\begin{array}{l}\text { Annual and seasonal time series of index selected from } \\
\text { the ETCCDI list (Table 1) for the unique spatially } \\
\text { averaged daily precipitation across the region }\end{array}$ & Index estimates per year and per year per season \\
\hline
\end{tabular}




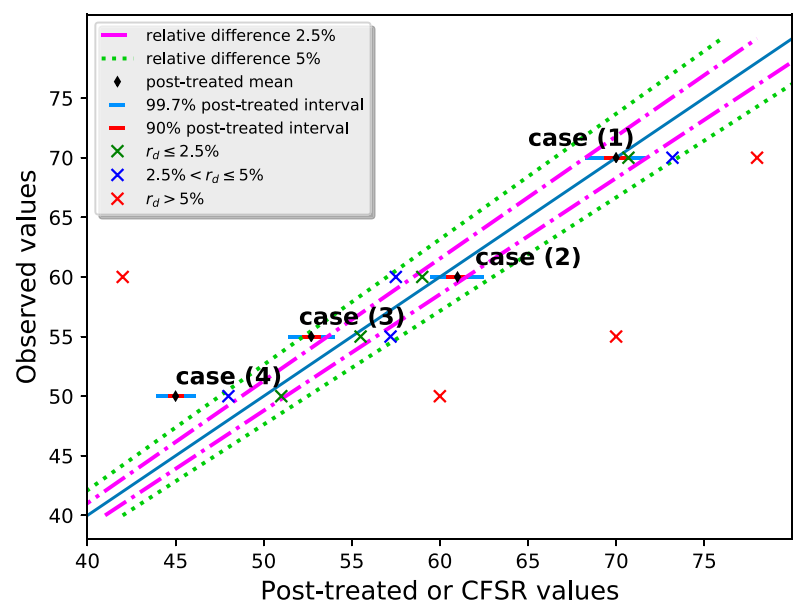

FIG. 3. Four possible cases when comparing CFSR (crosses) or postprocessed (confidence intervals) results to observations: case 1 is for good performance ( $90 \%$ simulated intervals), cases 2 and 3 are for fair performance, and case 4 is for poor performance. CFSR performances (crosses) for the four cases were considered good, fair, or poor if the relative differences with the observations $r_{d}$ were $\leq 2.5 \%,>2.5 \%$ and $\leq 5 \%$, or $>5 \%$, respectively. [Adapted from Bennett et al. (2018).]

therefore computed. CFSR and post-processed annual cycles were then compared to observed cycles through the Pearson correlation coefficient.

Annual and seasonal precipitation indices were selected among the Joint Commission for Climatology (CCl)/CLIVAR/JCOMM Expert Team on Climate Change Detection and Indices (ETCCDI) list (Peterson et al. 2001). They are related to three main attributes of precipitation: 1) persistence through the annual maximum length of wet and dry spells (CDW and CDD); 2) frequency of daily precipitation for moderate annual precipitation events (R10mm and $\mathrm{R} 20 \mathrm{~mm}$ ); and 3) intensity for various precipitation regimes (PRCPTOT, Rx1day, Rx5day, R95p and R99p; see Table 1 for descriptions of all indices). All indices were estimated for each year (e.g., PRCPTOT characterizes the precipitation annual amount for each year).

Initially developed to compare characteristic climate means or distributions (Baxevani and Lennartsson 2015), the CASE framework was slightly adapted for the annual ETCCDI indices to allow year-to-year analyses. Each ensemble of the 100 post-processed indices $\left\{\mathrm{I}_{\mathrm{sim}_{k}}^{(j)}\right\}_{k \in[1,100]}$ was compared to the corresponding $\mathrm{I}_{\text {obs }}^{(j)}$ within the CASE framework, where $j, \operatorname{sim}_{k}$, and $I$ correspond to a given year, the $k$ th simulation, and one ETCCDI index, respectively. The results were reported as the fraction of years being classified as good, fair, or poor at each site and for each index (see section 5).

\section{2) Spatial evaluation}

The spatial evaluation was based on the empirical covariograms of the daily precipitation, smoothed with
LOESS curves (Cleveland and Devlin 1988), for the three different datasets (observed, CFSR, and 100 post-processed). The proportion of days being simultaneously dry or wet for each pair of sites was estimated to test the spatial intermittence of the precipitation and also to evaluate the chosen covariance function. The aim here was to jointly assess the spatial structure of the occurrence and the intensity of the daily precipitation (Baxevani and Lennartsson 2015).

As suggested by Kleiber et al. (2012) and Baxevani and Lennartsson (2015), spatiotemporal characteristics of the post-processed, observed, and CFSR precipitation fields are also relevant to assess simultaneously the spatial and temporal structure in the models. To this end, the precipitation was spatially averaged across the region for each day, and only days with valid observed values were considered in the analysis. The regionalaveraged daily time series were used to estimate the following ETCCDI indices: PRCPTOT, Rx1day, and Rx5day. The annual cycle was finally examined with the regional series to investigate the extent to which postprocessed and CFSR reproduced the monthly precipitation evolution at the domain scale.

\section{Results and discussion}

\section{a. Selection of the post-processing models}

Several GLMs and VGLMs were tested for the calibration period by sequentially adding linear predictors (seasonal terms and CFSR precipitation) in the parameters of the occurrence and intensity distributions. The most appropriate model for both distributions was selected using the Akaike information criterion (AIC; Akaike 1974). According to AIC, the precipitation occurrence was better modeled with seasonal terms for all sites, that is, with $\left[\alpha_{0}, \alpha_{1}, \alpha_{2}, \alpha_{3}\right] \neq 0$ [Eq. (1)]. With regard to the intensity modeling, three VGLM nested models, presented in Table 3, were tested for the post-processing. The S-MS model, that is, with $\left[\eta_{0}, \eta_{1}, \eta_{2}, \eta_{3}\right] \neq 0$ and $\left[\beta_{0}, \beta_{1}\right] \neq 0$ [Eq. (3)], was selected at all sites, according to AIC.

The two-parameter isotropic Matérn function (Stein 1999) was selected to model the empirical spatial covariance structure and was therefore used for the metaGaussian random field:

$$
\begin{aligned}
C(h)= & \frac{1}{2^{\nu-1} \Gamma(\nu)}\left(\sqrt{2 \nu} \frac{h}{a}\right)^{\nu} K_{\nu}\left(\sqrt{2 \nu} \frac{h}{a}\right), \\
& a>0, h \geq 0, \nu \geq 0,
\end{aligned}
$$

where $a$ denotes the scale parameter, $\nu$ the order of the modified Bessel function $K_{\nu}($.$) of the second kind, \Gamma($. the gamma function, and $h$ the distances between the 
TABLE 3. List of the nested VGLM models used to post-process precipitation intensity [see Eq. (3) and section 3a for the terminology and definition of variables].

\begin{tabular}{llr}
\hline \hline \multicolumn{1}{c}{ Model name } & \multicolumn{1}{c}{ Daily mean parameter function $h\left(\mu_{i}\right)$} & $\begin{array}{c}\text { Daily shape parameter } \\
\text { function } h\left(\gamma_{i}\right)\end{array}$ \\
\hline Nonseasonal conditional mean (NS-M) & \multicolumn{1}{c}{$\eta_{0}+\eta_{1} \log \left(x_{i}+1\right)$} & $\beta_{0}$ \\
Nonseasonal conditional mean and shape (NS-MS) & $\eta_{0}+\eta_{1} \log \left(x_{i}+1\right)$ & $\beta_{0}+\beta_{1} \log \left(x_{i}+1\right)$ \\
Seasonal conditional mean and shape (S-MS) & $\eta_{0}+\eta_{1} \log \left(x_{i}+1\right)+\eta_{2} \cos \left(\frac{2 \pi d}{T}\right)+\eta_{3} \sin \left(\frac{2 \pi d}{T}\right)$ & $\beta_{0}+\beta_{1} \log \left(x_{i}+1\right)$ \\
\hline
\end{tabular}

pairs of sites. The parameters in Eq. (6) were estimated for the calibration period. Figure $\mathrm{S} 2$ in the supplementary material displays the empirical covariogram as well as the four tested covariance functions (stable, Cauchy, Whittle, and Matérn functions).

\section{b. At-site daily statistic performance}

Figure 4 shows the at-site daily statistics for the CFSR and post-processed series compared to the observations. Post-processed daily mean precipitation on wet days, the 95th percentile of the daily precipitation, and the number of wet days clearly outperformed corresponding CFSR estimates. For the calibration period, $92 \%$ or more of the sites (up to $99 \%$ for the mean precipitation values) showed good performance, while the performance for the remaining sites was fair.

Although performance globally decreased over the validation period, it remains satisfactory as the performance at $80 \%$ of the sites was ranked as either good or fair. Of the sites with a fair or good performance, regardless of the considered period (calibration or validation), at least $73 \%$ of sites (bars above graphs in Fig. 4) had post-treated values outperforming those from CFSR. This means that when a site was good (fair) for a given post-processed characteristic value, then the associated CFSR value was classified as fair or poor (poor).

At the seasonal scale for the validation period, Table 4 shows that post-processed daily mean precipitation and precipitation on wet days were by far better represented during spring (MAM) and autumn (SON) than winter (DJF) and summer (JJA), with more than $98 \%$ (MAM) and $93 \%(\mathrm{SON})$ of sites displaying good or fair performances. These percentages decrease to less than $71 \%$ for winter (DJF) and less than 54\% for summer (JJA) as post-processed estimates generally underestimated observed values (not shown for conciseness). Similar rankings among seasons were observed over the calibration period but with a globally better performance (see Table S1).

The 95th percentile of the daily precipitation distribution was also adequately reproduced during MAM and SON, with almost $100 \%$ of sites with post-processed values having a good or fair performance, while these percentages were of the order of around $75 \%$ for DJF and JJA. Again, performance for post-processed series was superior to that of CFSR for a majority of sites. These results demonstrated that the post-processing approach significantly improved at-site daily statistics at both annual and seasonal scales but with the same ranking in terms of performances between seasons (see Table S1).

The transition probabilities of having two consecutive dry days $p_{00}$ and of having a wet day preceded by a dry day $p_{01}$ as estimated by observed series and postprocessed series are presented in Fig. 5 for both calibration and validation periods. The two post-processed transition probabilities displayed good or fair performances at a majority of sites, around $80 \%-90 \%$ for the validation and calibration periods, respectively. The other two probabilities, $p_{11}$ and $p_{10}$, displayed very similar performances (Fig. S3). These probabilities estimated from post-treated series systematically outperformed those estimated from CRSR at all sites for both the calibration and validation periods (not shown for conciseness). The seasonal analysis (see Fig. S4) showed that a lower percentage of sites was in the good category during MAM and SON than during DJF and JJA. As expected, the performance over the validation period slightly decreased compared to calibration but post-treated estimates still outperformed CFSR ones.

Figure 6 summarizes the seasonal probabilities of occurrence of wet spells of various durations for calibration and validation periods. For a given season, performance for wet spell probabilities improved as duration increased. For instance, for MAM during calibration, the percentages of sites with post-processed probabilities classified in the good (fair) category range from $26 \%(26 \%)$ for $p_{\text {wet }}^{(1)}$ to $91 \%(8 \%)$ for $p_{\text {wet }}^{(5)}$. The $p_{\text {wet }}^{(1)}$ values were generally underestimated in postprocessed series and to a greater extent overestimated in CFSR, while the opposite is observed for longer durations regardless of the considered period (calibration/validation). Such results may be explained by the so-called drizzle effect (Dai 2006). Seasonal differences in performance were more important for shorter-duration events, with MAM having the lowest percentages of 
Calibration
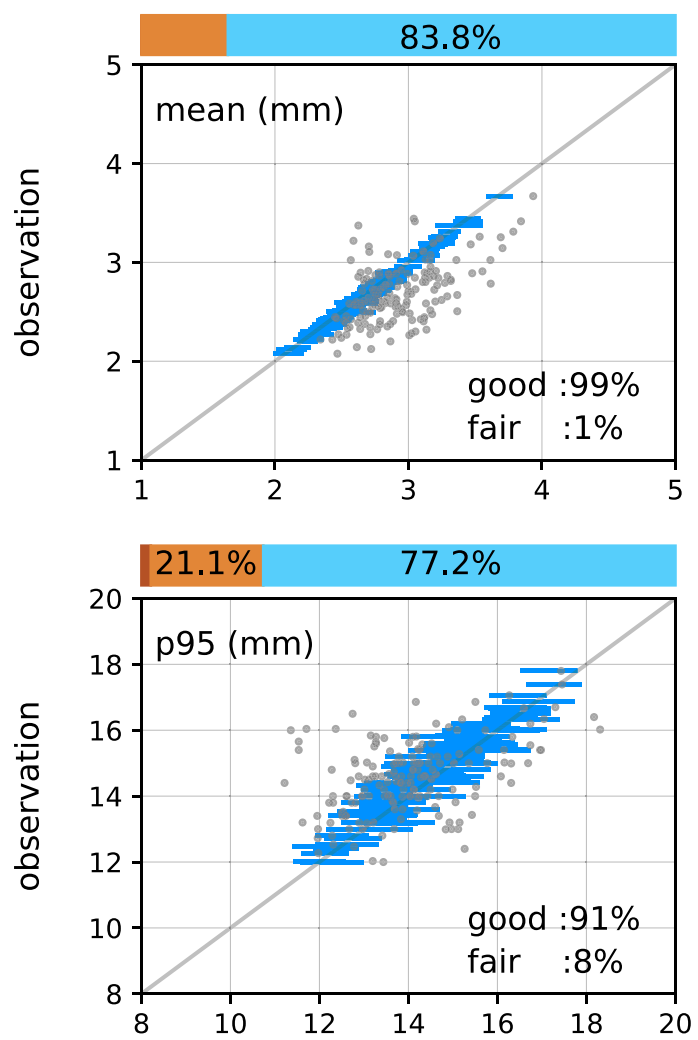

Validation
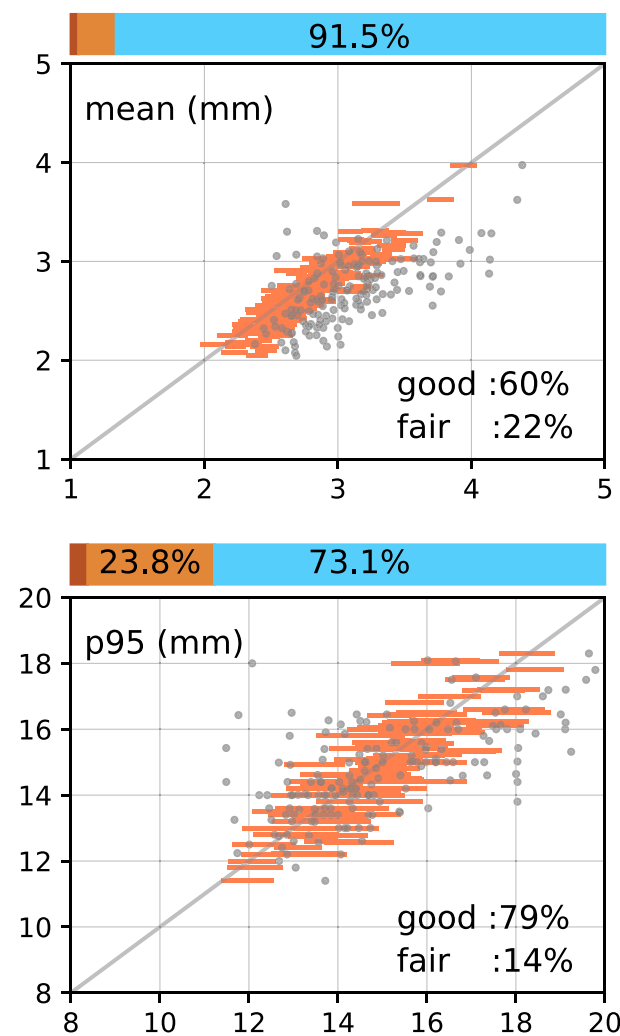
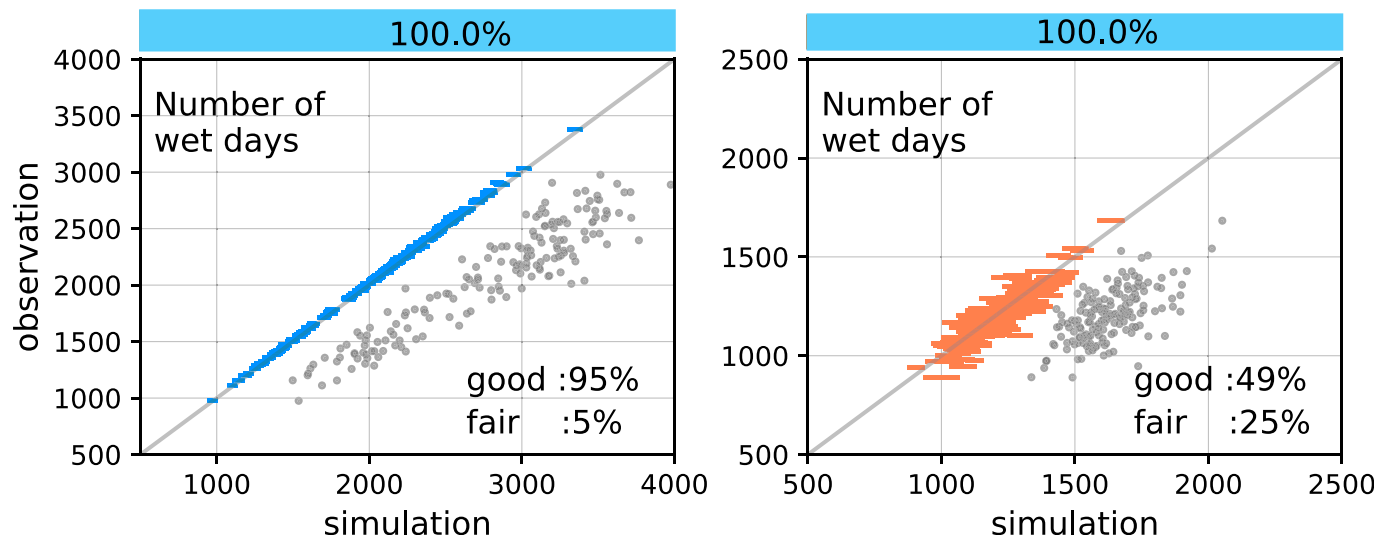

FIG. 4. At-site (top) precipitation mean, (middle) 95th percentile (p95), and (bottom) number of wet days estimated from recorded series ( $y$ axis) as a function of the corresponding values estimated from post-processed [ $[90 \%$ confidence interval; blue and orange lines for (left) calibration and (right) validation periods] or CFSR daily series (gray points). Proportions of sites with good and fair performances are indicated in the bottom-right corner of each panel. The scale above each panel indicates the percentages of sites with good or fair performances after postprocessing that displayed better (pale blue), similar (pale brown), or poorer (dark brown) performances compared to CFSR (percentages are not indicated when below $20 \%$ ).

sites in the good or fair category (around $50 \%$ during the calibration period). These differences decreased as the duration increased. Similar conclusions can be reached when comparing results for the calibration and validation periods with very small differences for longer durations $\left(p_{\text {wet }}^{(5)}\right)$. Surprisingly, better performance was obtained for the validation than for the calibration period for many seasons and durations.

Performance for dry spells remained similar across durations and seasons (see Fig. S5) and were better than 
TABLE 4. Percentage of sites with post-processed statistics (columns) being in the good or fair categories for each season (rows) for the validation period. Numbers in parentheses indicate the percentage of sites in the good or fair categories with improved (first number), similar (second number), or poorer performances (third number) compared to CFSR. For instance, for the post-processed daily DJF mean precipitation (first line, first column entry), of the $71 \%$ of sites with post-processed good or fair performances $96 \%$ outperformed CFSR, $3 \%$ displayed similar performances, and $1 \%$ were outperformed by CFSR.

\begin{tabular}{|c|c|c|c|c|c|}
\hline & $\begin{array}{l}\text { Daily mean } \\
\text { precipitation }\end{array}$ & $\begin{array}{c}\text { Daily mean precipitation } \\
\text { on wet days }\end{array}$ & $\begin{array}{l}\text { Std dev of daily } \\
\text { precipitation }\end{array}$ & $\begin{array}{l}p_{95} \text { of daily } \\
\text { precipitation }\end{array}$ & No. of wet days \\
\hline DJF & $\begin{array}{c}71 \\
(96,3,1)\end{array}$ & $\begin{array}{c}84 \\
(98,2,0)\end{array}$ & $\begin{array}{c}100 \\
(91,8,1)\end{array}$ & $\begin{array}{c}75 \\
(89,11,0)\end{array}$ & $\begin{array}{c}71 \\
(100,0,0)\end{array}$ \\
\hline MAM & $\begin{array}{c}98 \\
(70,24,6)\end{array}$ & $\begin{array}{c}99 \\
(83,17,0)\end{array}$ & $\begin{array}{c}99 \\
(91,8,1)\end{array}$ & $\begin{array}{c}98 \\
(69,26,5)\end{array}$ & $\begin{array}{c}90 \\
(71,29,0)\end{array}$ \\
\hline JJA & $\begin{array}{c}54 \\
(68,25,7)\end{array}$ & $\begin{array}{c}65 \\
(88,12,0)\end{array}$ & $\begin{array}{c}89 \\
(90,9,1)\end{array}$ & $\begin{array}{c}76 \\
(74,23,3)\end{array}$ & $\begin{array}{c}73 \\
(72,28,0)\end{array}$ \\
\hline SON & $\begin{array}{c}95 \\
(71,23,6)\end{array}$ & $\begin{array}{c}93 \\
(83,17,0)\end{array}$ & $\begin{array}{c}98 \\
(91,8,1)\end{array}$ & $\begin{array}{c}98 \\
(69,25,5)\end{array}$ & $\begin{array}{c}91 \\
(72,28,0)\end{array}$ \\
\hline
\end{tabular}

for wet spells. During the validation period, at least $80 \%$ and up to $95 \%$ of sites displayed good performance while the remaining sites fell into the fair category. These percentages were even more important when considering the calibration period. Finally, for the calibration and validation periods, the probability of occurrence of both wet and dry spells estimated from post-treated series outperformed the CFSR estimates.
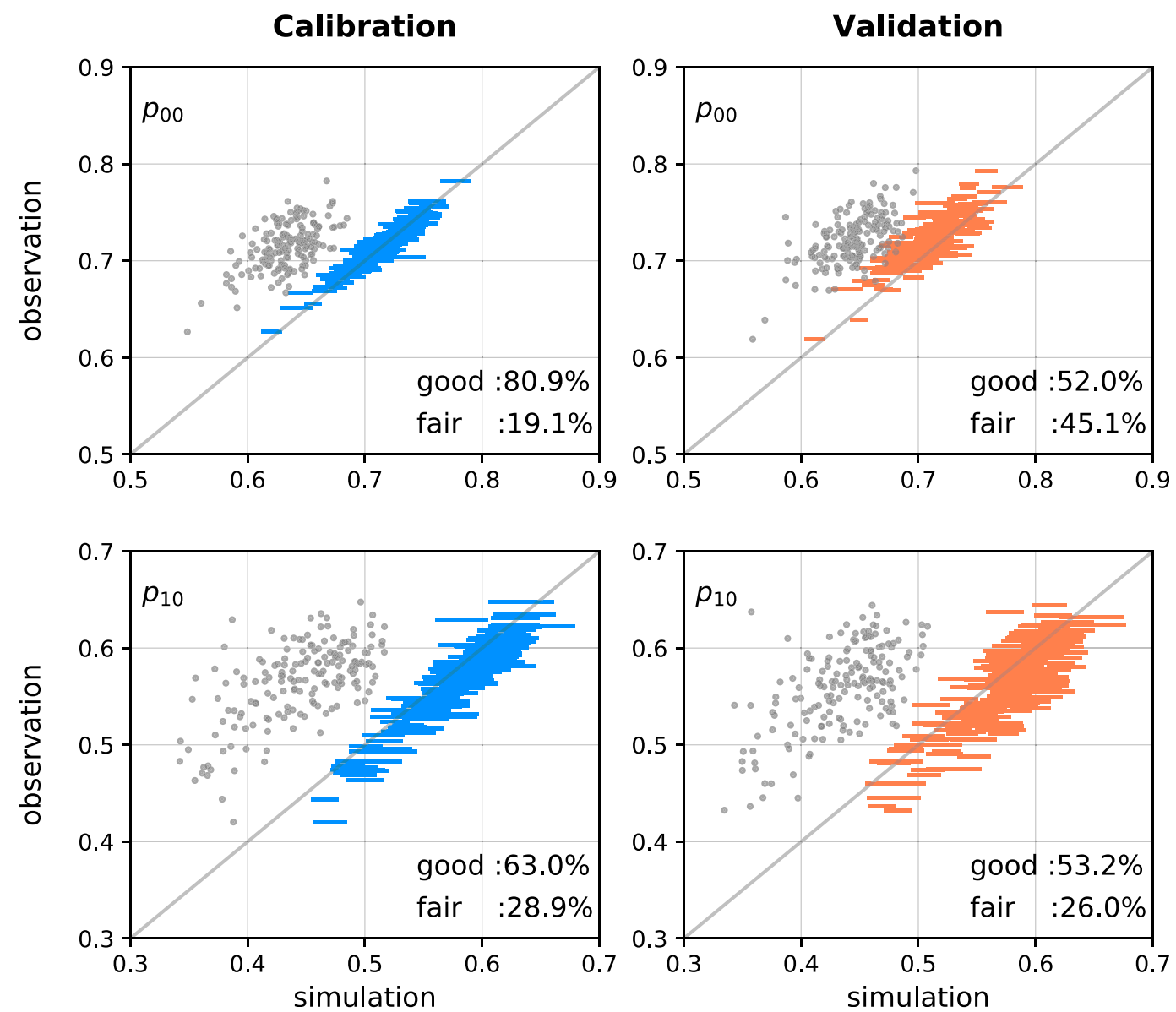

FIG. 5. At-site two-state transition probabilities $p_{00}$ and $p_{10}$ (dry, 0 ; wet, 1 ) estimated from the observed series as a function of the corresponding values estimated from the post-processed ( $90 \%$ confidence interval; blue and orange lines for calibration and validation periods, respectively) or CFSR daily time series (gray points). Proportions of sites with good and fair performances are indicated in the bottom-right corner of each panel. 

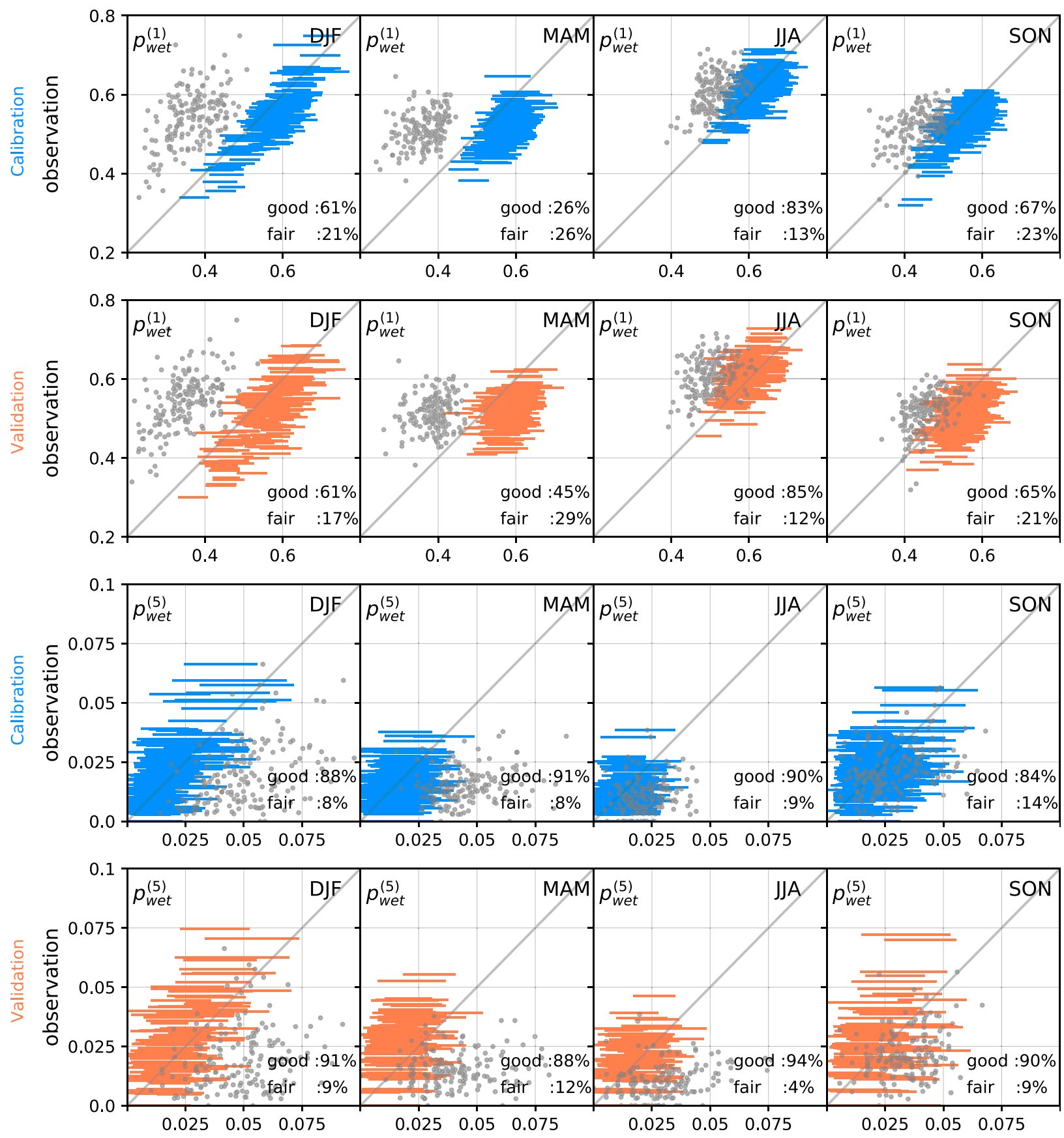

FIG. 6. At-site seasonal probabilities of occurrence of wet spells of various durations ( 1 and 5 days) $\left(p_{\text {wet }}^{(\text {duration })}\right)$ estimated from observed series as a function of the corresponding values estimated from the post-processed $(90 \%$ confidence interval; blue and orange lines correspond to calibration and validation periods, respectively) or CFSR daily time series (gray points). Proportions of sites with good and fair performances are indicated in the bottom-right corner of each panel.

Results for the post-processed daily series autocorrelation showed that $69 \%(28 \%), 45 \%(34 \%)$, and $84 \%$ $(13 \%)$ of the sites displayed good (fair) performance for, respectively, lag-1, lag-2, and lag-3 autocorrelations during the validation period. Better performances were estimated when considering the calibration period.
Furthermore, all autocorrelation statistics were systematically improved when compared to CFSR.

Pearson's correlation coefficients between the observed monthly precipitation averaged over the calibration and validation periods and corresponding values from CFSR and post-processed series were estimated (see Fig. S6). 

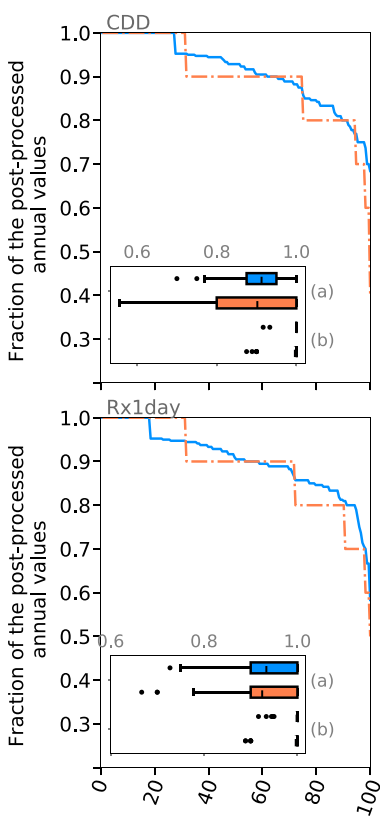

Fraction of the sites \%
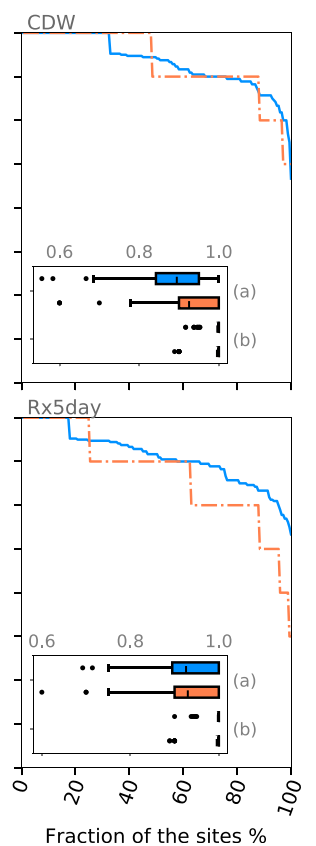
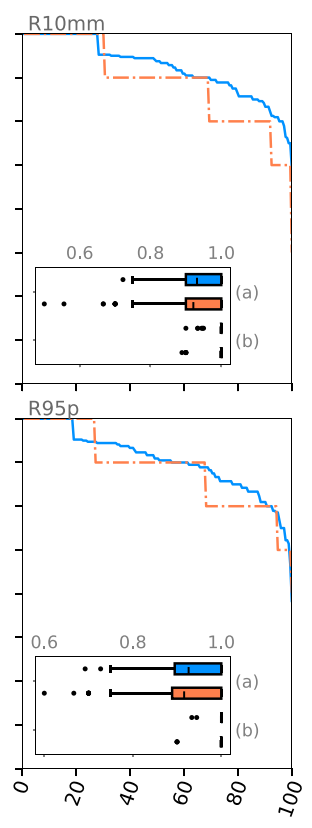

Fraction of the sites \%
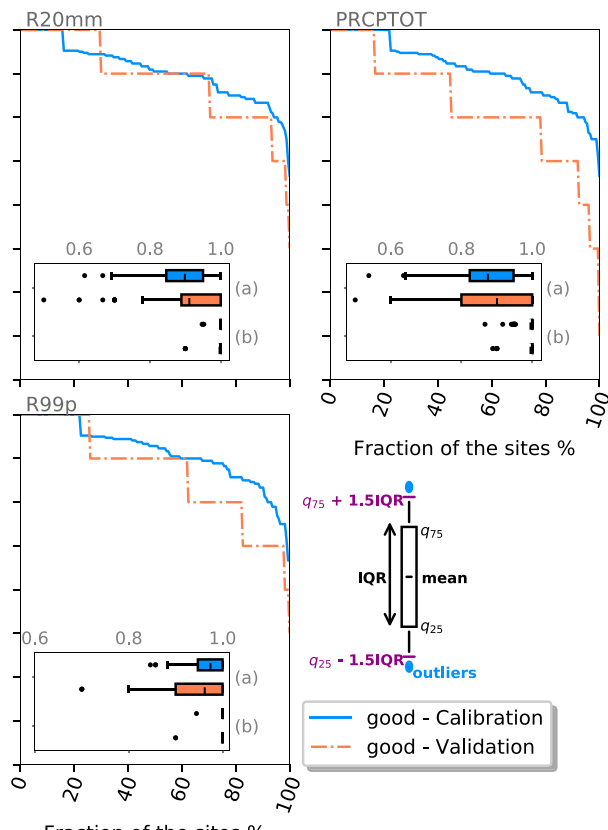

Fraction of the sites \%
Fraction of the sites \%
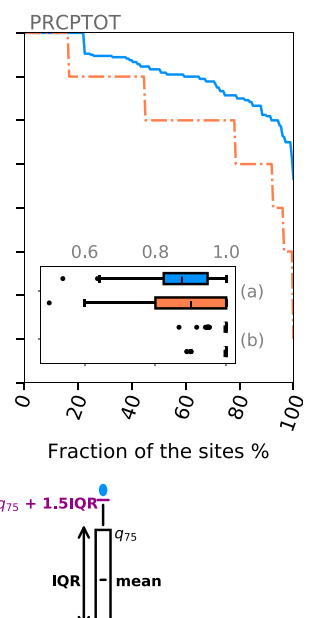

$q_{25}-1.5 I_{Q R}{ }^{-}$

good - Calibration good - Validation

FIG. 7. Fraction of the sites with a given fraction of post-processed annual ETCCDI values in the good category. Fractions of annual index values are ranked in decreasing order and the corresponding fraction of sites is given along the $x$ axis. For example, for the (top left) CDD index around $20 \%$ of the sites have all annual values in the good category for the calibration period. Blue and orange colors refer to the calibration and validation period, respectively. The boxplot in each panel shows the distribution of the proportion of post-processed annual index values classified in the good or fair categories that (a) strictly outperformed CFSR or (b) displayed similar performance to CFSR or outperformed CFSR. The boxplot definition is shown at the bottom-right corner with IQR meaning interquartile range.

For both the calibration and validation periods, the CFSR correlations were significantly improved at almost all sites with post-processed median correlation values ranging from 0.6 to 0.9 , while CFSR correlations were rather poor with correlations below 0.5 (even negative in some cases) for almost $70 \%(25 \%)$ of stations for the calibration (validation) period.

\section{c. At-site ETCCDI index performance}

Performances regarding annual or seasonal ETCCDI index series (comparison of post-treated annual or seasonal values to the corresponding observed values) are illustrated, respectively, in Figs. 7 and 8 . The short length $(10 \mathrm{yr})$ of the validation period explained the stepwise structure of the curves in Figs. 7 and 8. The performances were very similar for calibration and validation periods (only years with good performances are presented for conciseness). A large number of sites displayed post-processed annual index series with high numbers of years in the good and fair categories. For both periods, each post-treated index value of the annual series was classified in the good category for all indices and for approximately $20 \%$ of the sites. In comparison, for about $40 \%$ of the sites the percentage of annual values classified as good ranged from $90 \%$ to $95 \%$, and for $30 \%$ of the sites this percentage was generally above $80 \%$. For many sites, a large fraction of years that were not classified as good were classified as fair (not shown for conciseness).

Small differences among the indices can be observed. For instance, the post-processed CDW series more likely have annual values in the good category than the post-processed CDD series. Indices characterizing moderate extreme events, such as R10mm and R95p, also had their performances degraded when extreme events were even more extreme (i.e., R20mm and R99p). This may be partly explained by the light tail of the gamma distribution preventing the capture of heavy precipitation. Lower performance for PRCPTOT was explained by the relatively small $90 \%$ confidence intervals for the post-treated series leading to less likely classifications of post-treated PRCPTOT values in the good category. Comparisons at the seasonal time scale are presented in Fig. 8. Post-processing performance was systematically lower during JJA, as previously mentioned (see section 5b). However, more than $90 \%$ of the annual series for all indices and more than $90 \%$ of sites were in the good or fair categories for all seasons, with the only exception being the PRCPTOT index during JJA (see Fig. S6). Finally, comparing the performance of post-processed series to those of CFSR indicated that, for given sites and indices, on average 

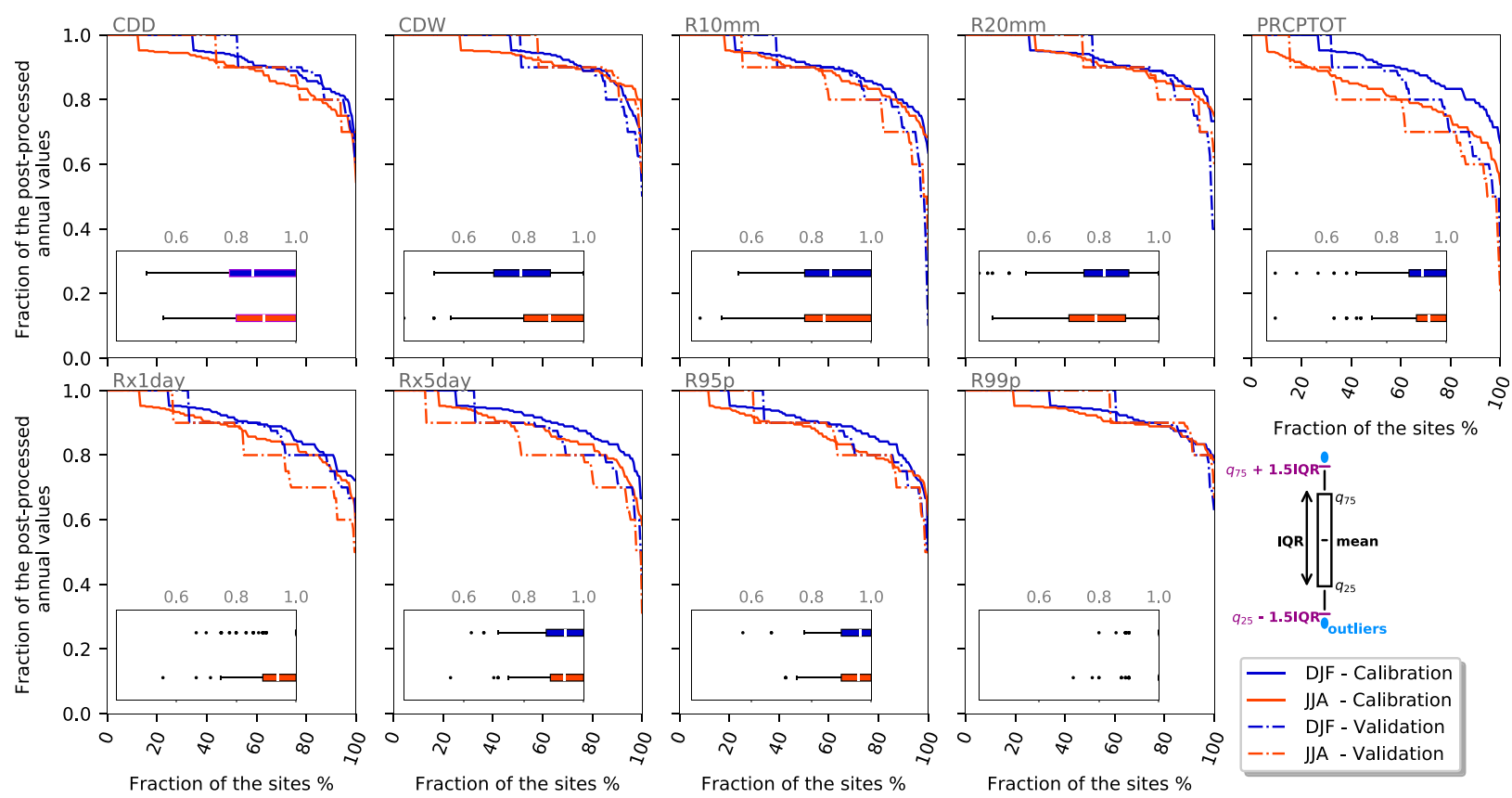

FIG. 8. As in Fig. 7, but for the fraction of the sites with a given fraction of post-processed annual ETCCDI values in the good category for DJF (blue) and JJA (red).

around $95 \%$ of the post-processed annual values in the good and fair categories (see Fig. 7a) outperformed the corresponding CFSR values. This percentage averaged from $80 \%$ to $90 \%$ (see boxplots in Fig. S6) at the seasonal scale. Generally, years for which the post-processed index performances were not better than for CFSR displayed similar performances to CFSR (see Fig. 7b and Fig. S6).

\section{d. Spatial evaluation}

Spatial correlations between post-processed, CFSR, and observed daily precipitation series for all pairs of sites were estimated at the annual and seasonal time scales (Fig. 9). Similar correlation values were obtained for both the calibration and validation periods. Although overestimated, the seasonal dependence of spatial correlation obtained from CFSR is consistent with that estimated from the observations (e.g., weaker correlations in summer and larger in winter). Slight overestimations of the post-processed spatial correlations, at relatively short $(<250 \mathrm{~km})$ and at very large distances $(>750 \mathrm{~km})$, were obtained during each season. Otherwise, for distances between 250 and $750 \mathrm{~km}$, the observed correlation fell in the good category during JJA, and even at the yearly scale, poorer performances were observed during DJF. The strong hypothesis of spatial isotropy may partly explain these performances, especially during winter when snow accumulation is more likely south of the Great Lakes (lake-effect snow; LucasPicher et al. 2017). The use of covariance functions to fit scattered empirical spatial correlations may also contribute to these discrepancies.

The proportions of simultaneous wet days for each pair of sites were also estimated (Fig. 10) to assess the ability of the latent Gaussian field to represent the spatial distribution of wet sites. Results showed that during DJA and JJA for approximately $85 \%(80 \%)$ of cases (pairs of stations and days) the frequency of simultaneous wet days was in the good or fair categories for the calibration (validation) period. A similar analysis was carried out for dry days (see Fig. S6) with similar results.

PRCPTOT and Rx1day annual series averaged over the study area are presented in Fig. 11. Post-processed series fell within the good performance intervals, while CFSR broadly produced fair performances over many years, mainly because of poor performances during the DJF and MAM seasons (Fig. S8) for both the calibration and validation periods. Very similar results were obtained for Rx5day and are not shown for conciseness.

Finally, the annual cycle, computed with spatially averaged daily precipitation, was significantly improved by the post-processing method as shown in Fig. 12. The annual cycle estimated from the validation period was noisier, which is mainly due to the shorter records for this period. The shape of the annual cycle with its plateau from June to December and its lower precipitation in February were adequately reproduced in the post-processed series, even during the validation time period. Almost all months were 


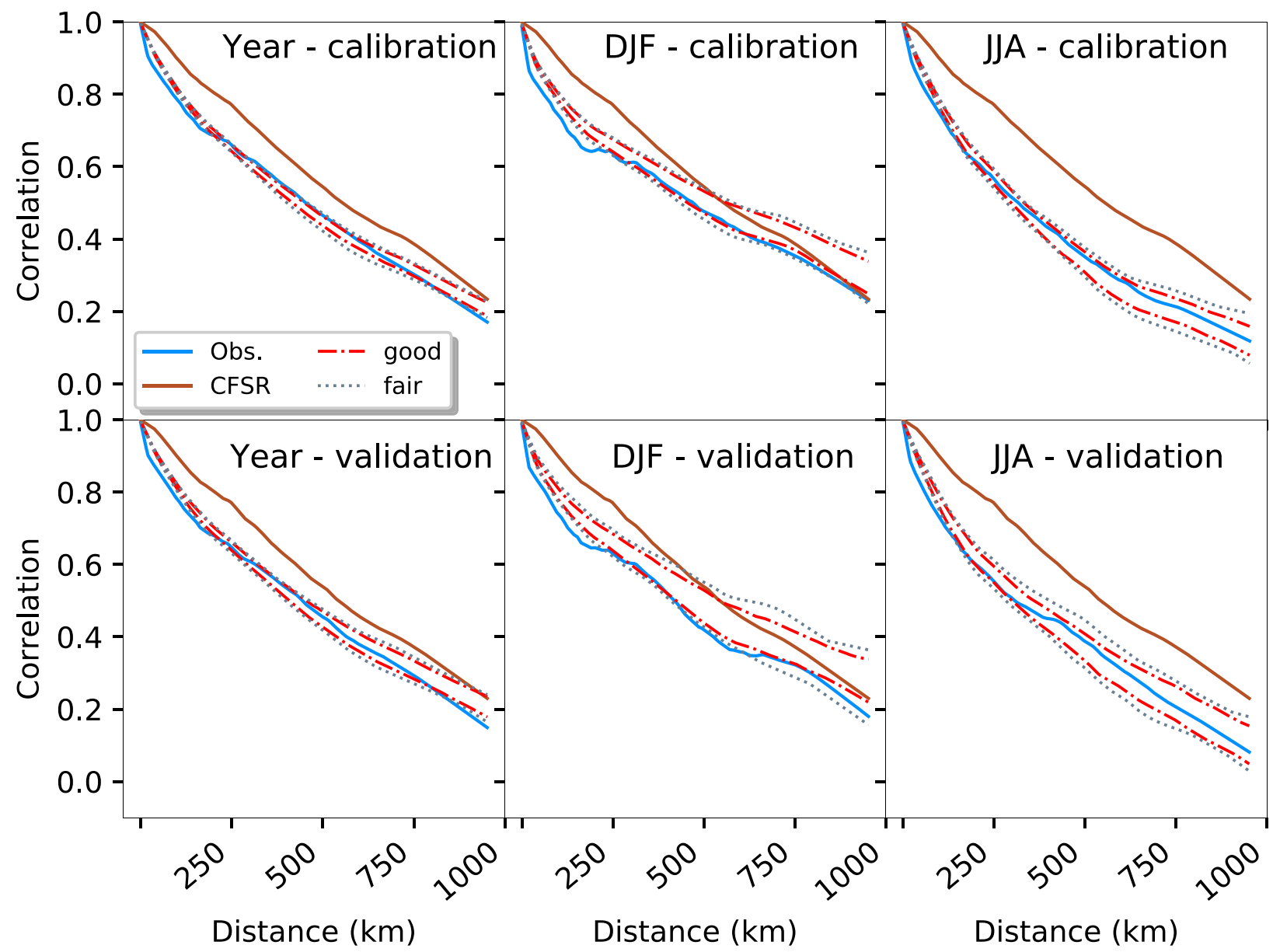

FIG. 9. Spatial correlations of the daily precipitation series at the annual and seasonal (DJF and JJA) time scales for observed (blue) and CFSR (brown) datasets for the (top) calibration and (bottom) validation periods. The post-processed series are illustrated with the $90 \%$ (dashed red line, good) and $99.7 \%$ (dotted gray lines, fair) confidence intervals.

classified as good or fair and noticeable improvements were observed compared to CFSR.

\section{Conclusions}

This study aimed to post-process CFSR daily precipitation by using observed time series in order to provide continuous precipitation fields at the local scale. The key idea was to take advantage of the continuous and consistent reanalysis datasets, which are outputs from dynamically based models that assimilate, at a given time step (e.g., $6 \mathrm{~h}$ ), past observations, to get information at sites and during periods where no observed series are available. However, reanalyses should be post-processed as biases and scale mismatch with at-site observations exist. The main objective of this study was to evaluate a stochastic approach (Wong et al. 2014) combined with a meta-Gaussian random field model to post-process CFSR daily precipitation fields (Serinaldi and Kilsby 2014). Post-processed precipitation was compared to observations and CFSR without postprocessing for 172 sites across the Great Lakes region. Regression approaches were used to develop mixed daily precipitation distributions with local-scale properties by using CFSR and observations as, respectively, the predictor and predictand. The logistic regression and the more general VGLM framework were used to model, respectively, the occurrence and the intensity for wet days. Following Serinaldi and Kilsby (2014), one meta-Gaussian latent field was employed during the simulation stage to provide uniform random fields having spatial (correlograms) and temporal structures (autocorrelation lag-1) similar to the observed precipitation process. The latter fields were then used to simulate daily precipitation sequences from the local daily mixed precipitation distributions.

Seasonal covariance functions and the lag-1 autocorrelation were both used in the meta-Gaussian random 
Calibration

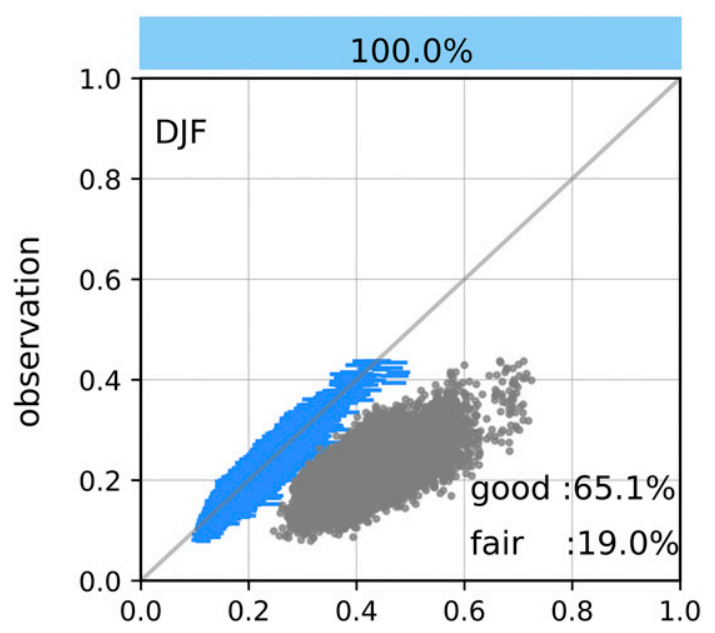

Validation

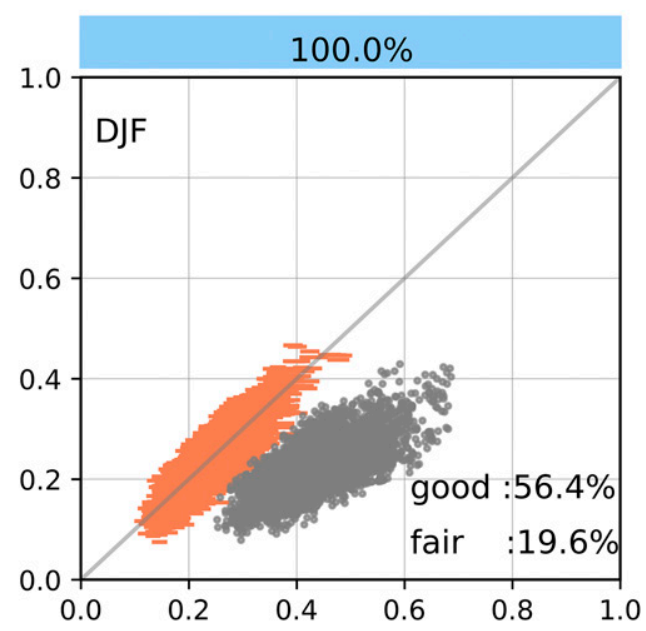

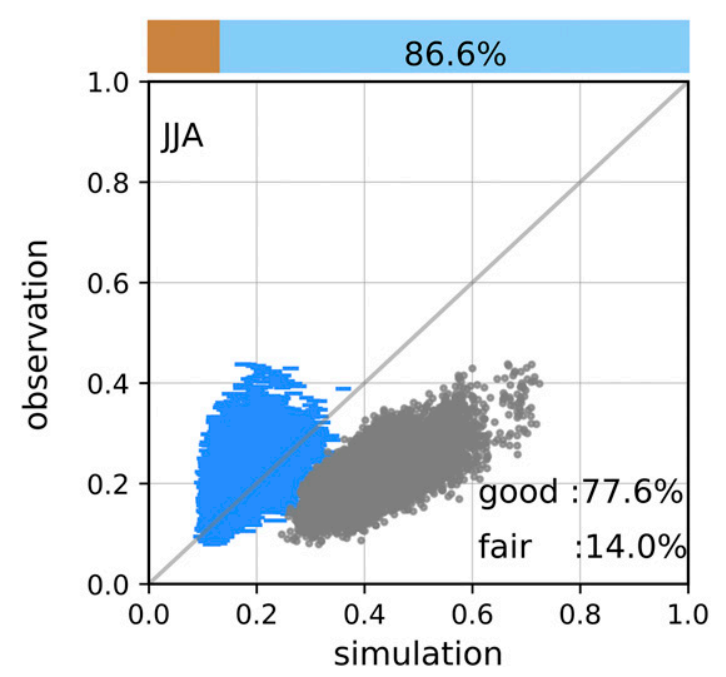

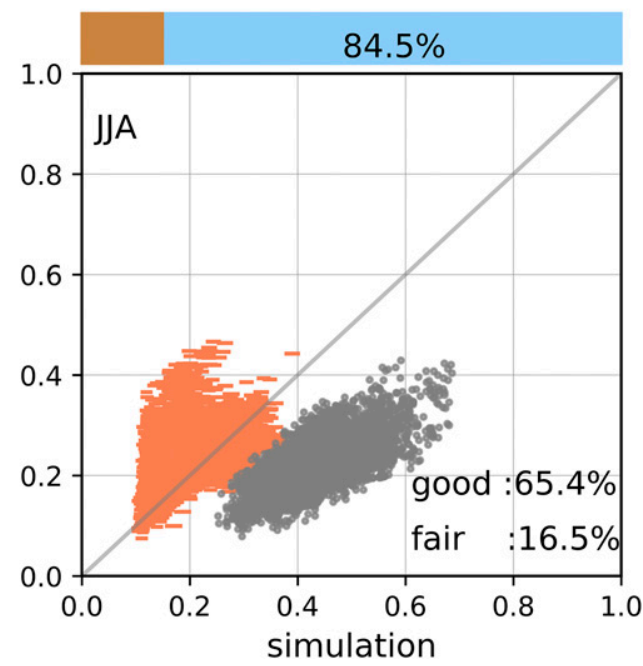

FIG. 10. Proportion of simultaneous wet days during the (left) calibration and (right) validation periods for each pair of sites during (top) DJF and (bottom) JJA estimated from observed series ( $y$ axis) and post-processed series ( $90 \%$ confidence interval represented by horizontal lines) or CFSR (gray dots). The scale above each panel indicates the percentage of sites with good or fair performances after post-processing that displays higher (pale blue), similar (pale brown), or lower (dark brown) performances compared to CFSR (percentages are not indicated when below 20\%).

field. One hundred daily precipitation series were randomly generated and assessed through daily statistics and chosen indices from the ETCCDI list at both the site and on regional scales. The framework developed by Bennett et al. (2018) was considered for evaluation, as it allows a simple and intuitive framework for the comparisons of observed, CFSR, and post-processed statistics. Three performance categories - called good, fair, and poor-were proposed based on how the post-processed interval or CFSR value compared to the corresponding values estimated from observations. Finally, all results were analyzed within a temporal calibration-validation framework by splitting daily precipitation series into a calibration period and a validation period.

The results have shown that the proposed postprocessing approach was able to reproduce several at-site daily statistics of the two marginal distributions (precipitation occurrences and intensity) with generally higher performances for calibration than for the validation periods. For almost all sites, post-processed estimates were classified in the good category. Generally, performances during winter and summer are lower although high proportions of sites remained in the good or fair category. These results may be partly explained 

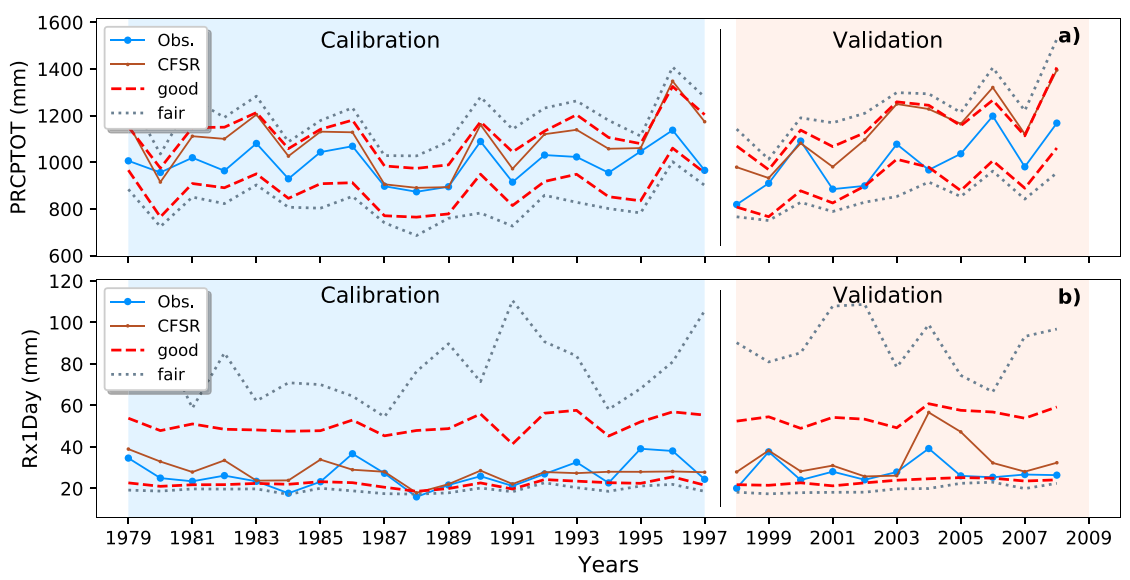

FIG. 11. (a) PRCPTOT and (b) Rx1day estimated at the domain scale from the observations (blue) and the CFSR (brown) dataset. The post-processed series are illustrated with the median values (black line with crosses) and the $90 \%$ (dashed red line, good) and $99.7 \%$ (dotted gray lines, fair) confidence intervals. Blue and orange backgrounds correspond, respectively, to the calibration and validation periods.

by the poorer performance of CFSR across the Great Lakes region during these seasons with likely convectiontype precipitation during summer and the snow lake effect during winter (Lucas-Picher et al. 2017). The postprocessing approach was also able to reproduce the temporal at-site persistence as well as the autocorrelation structure, the transition probabilities between wet and dry days, and the probabilities of occurrence of wet and dry spells of different durations. Moreover, the post-processed statistics were significantly improved compared to CFSR. Few inaccuracies were observed in representing the probability of occurrence of 1-day wet events during spring (MAM) with slight overestimations in the post-processed series. The year-to-year comparisons of the ETCCDI indices again demonstrated the high potential of the post-processing approach, as for all sites and for the majority of indices, high proportions (ranging from $85 \%$ to $100 \%$ ) of years were classified in the good category. Again, performances during winter and summer were lower. The post-processing model
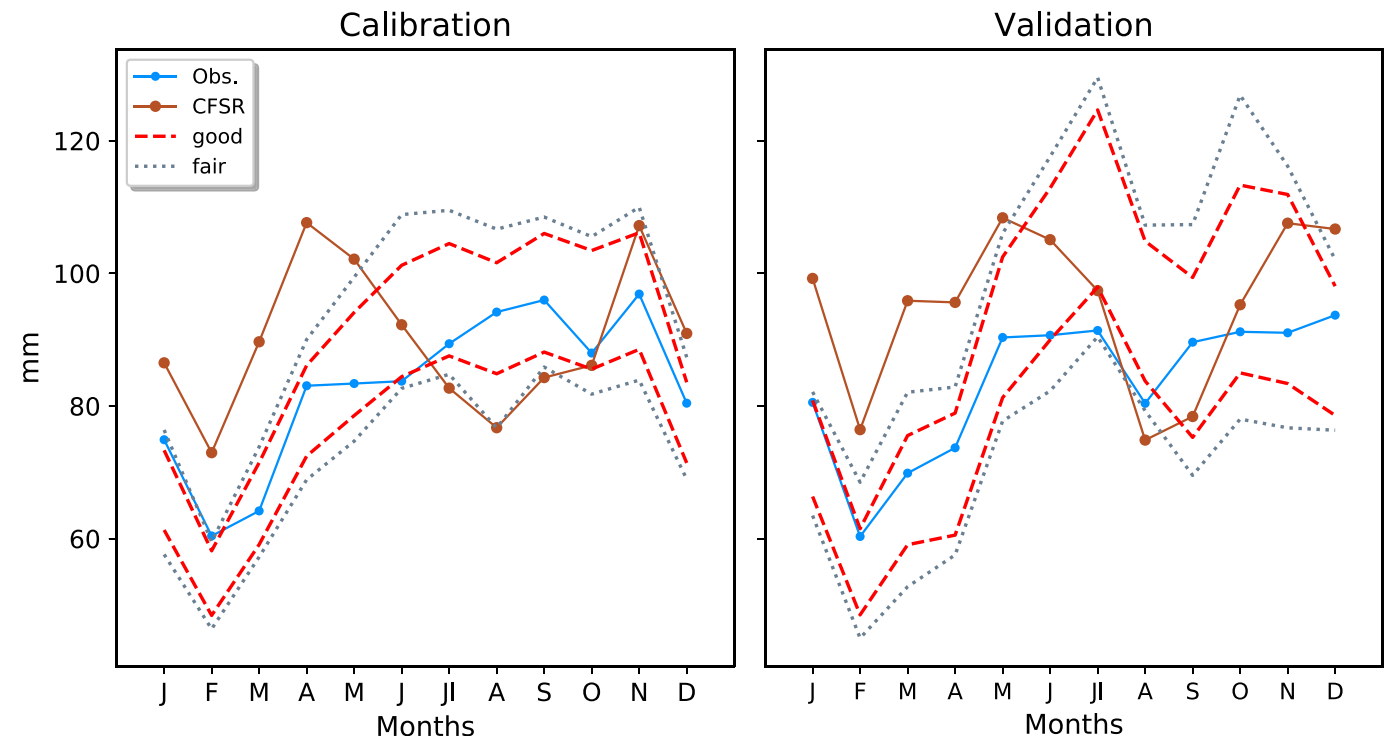

FIG. 12. Monthly precipitation averaged over the study region as estimated from observed (blue), CFSR (brown), and post-processed series. Median values (black line with crosses) and confidence intervals for post-processed values are presented (90\%, dashed red lines; $99.7 \%$, dotted gray lines). Shown are results for the (left) calibration and (right) validation periods. 
effectively captured the spatial correlation of the precipitation, with slight overestimations of the correlations at relatively short distances. The post-processed daily precipitation spatial correlations better reproduced the observed correlations than those obtained with CFSR, which systematically overestimate spatial correlation at all distances. Very similar CFSR and post-processed statistics related to domain-averaged daily precipitation were obtained, though the fair intervals in the postprocessing were large. Additionally, one interesting feature of the post-processed series was their ability to reproduce the annual cycle at the local and regional scales. Similar performances to those estimated for the calibration period, for all studied characteristics and indices, were obtained when considering series over the whole period of time; that is, there was no splitting into calibration/validation periods (not shown for conciseness).

In general, the proposed post-processing stochastic approach demonstrated a high potential for providing precipitation series that reproduce at-site statistics, indices, and the specific annual cycle of the Great Lakes region. Further research may include more complex spatial models by considering anisotropy, especially in the studied region where the large water bodies have an influence on the precipitation regimes. Other promising research avenues include the interpolation of at-site coefficients that characterize the local mixed daily precipitation distributions. Simulations of consistent precipitation fields, even at ungauged locations, would then be possible. To enhance estimates of the full precipitation range (including extremes), more heavytailed distributions, such as the probability mixture model of gamma and generalized Pareto (GP) distributions (Vrac and Naveau 2007; Wong et al. 2014) or the extended GPD model (EGPD) of Naveau et al. (2016), should be considered. A systematic comparison to other post-processing approaches (e.g., analog method; Boé et al. 2006) should be considered in future work to help users identify the methodologies that best suit their needs. Finally, the generalization of this approach to regional climate model outputs would offer interesting tools for hydrological modeling in a changing climate.

Acknowledgments. The authors thank Eva Mekis from Environment and Climate Change Canada, who provided the daily series from the Adjusted Precipitation for Canada (APC2) dataset, the Ministère du Développement Durable, de l'Environnement et de la Lutte contre les Changements Climatiques (MDDELCC) of Québec (data available upon request; info-climat@mddelcc.gouv.qc.ca) for the daily records, and Silvia Innocenti for useful discussions. This research was partly funded by a Collaborative Research and Development Grant (CRDPJ 435692-12) from the Natural Sciences and Engineering Research Council of Canada (NSERC).

\section{REFERENCES}

Akaike, H., 1974: A new look at the statistical model identification. IEEE Trans. Automat. Contr., 19, 716-723, https://doi.org/ 10.1109/TAC.1974.1100705.

Asong, Z. E., M. N. Khaliq, and H. S. Wheater, 2016: Multisite multivariate modeling of daily precipitation and temperature in the Canadian Prairie Provinces using generalized linear models. Climate Dyn., 47, 2901-2921, https://doi.org/10.1007/ s00382-016-3004-z.

Bardossy, A., and E. J. Plate, 1992: Space-time model for daily rainfall using atmospheric circulation patterns. Water Resour. Res., 28, 1247-1259, https://doi.org/10.1029/91WR02589.

Baxevani, A., and J. Lennartsson, 2015: A spatiotemporal precipitation generator based on a censored latent Gaussian field. Water Resour. Res., 51, 4338-4358, https://doi.org/10.1002/ 2014WR016455.

Beaulieu, C., O. Seidou, T. B. M. J. Ouarda, X. Zhang, G. Boulet, and A. Yagouti, 2008: Intercomparison of homogenization techniques for precipitation data. Water Resour. Res., 44, W02425, https://doi.org/10.1029/2006WR005615.

Beck, H. E., A. I. J. M. van Dijk, V. Levizzani, J. Schellekens, D. G. Miralles, B. Martens, and A. de Roo, 2017: MSWEP: 3-hourly 0.25 global gridded precipitation (1979-2015) by merging gauge, satellite, and reanalysis data. Hydrol. Earth Syst. Sci., 21, 589-615, https://doi.org/10.5194/hess-21-589-2017.

Behrangi, A., Y. Tian, B. H. Lambrigtsen, and G. L. Stephens, 2014: What does CloudSat reveal about global land precipitation detection by other spaceborne sensors? Water Resour. Res., 50, 4893-4905, https://doi.org/10.1002/2013WR014566.

Bengtsson, L., and J. Shukla, 1988: Integration of space and in situ observations to study global climate change. Bull. Amer. Meteor. Soc., 69, 1130-1143, https://doi.org/10.1175/ 1520-0477(1988)069<1130:IOSAIS>2.0.CO;2.

Bennett, B., M. Thyer, M. Leonard, M. Lambert, and B. Bates, 2018: A comprehensive and systematic evaluation framework for a parsimonious daily rainfall field model. J. Hydrol., $\mathbf{5 5 6}$, 1123-1138, https://doi.org/10.1016/j.jhydrol.2016.12.043.

Boé, J., L. Terray, F. Habets, and E. Martin, 2006: A simple statistical-dynamical downscaling scheme based on weather types and conditional resampling. J. Geophys. Res., 111, D23106, https://doi.org/10.1029/2005JD006889.

Bromwich, D. H., J. P. Nicolas, and A. J. Monaghan, 2011: An assessment of precipitation changes over Antarctica and the Southern Ocean since 1989 in contemporary global reanalyses. J. Climate, 24, 4189-4209, https://doi.org/10.1175/2011JCLI4074.1.

Buishand, T. A., and T. Brandsma, 2001: Multisite simulation of daily precipitation and temperature in the Rhine basin by nearest-neighbor resampling. Water Resour. Res., 37, 27612776, https://doi.org/10.1029/2001WR000291.

_ M. V. Shabalova, and T. Brandsma, 2004: On the choice of the temporal aggregation level for statistical downscaling of precipitation. J. Climate, 17, 1816-1827, https://doi.org/10.1175/ 1520-0442(2004)017<1816:OTCOTT>2.0.CO;2.

Chandler, R. E., and H. S. Wheater, 2002: Analysis of rainfall variability using generalized linear models: A case study from the west of Ireland. Water Resour. Res., 38, 1192, https:// doi.org/10.1029/2001WR000906. 
Cleveland, W. S., and S. J. Devlin, 1988: Locally weighted regression: An approach to regression analysis by local fitting. J. Amer. Stat. Assoc., 83, 596-610, https://doi.org/10.1080/01621459.1988.10478639.

Coe, R., and R. Stern, 1982: Fitting models to daily rainfall data. J. Appl. Meteor., 21, 1024-1031, https://doi.org/10.1175/15200450(1982)021<1024:FMTDRD>2.0.CO;2.

Contractor, S., L. V. Alexander, M. G. Donat, and N. Herold, 2015: How well do gridded datasets of observed daily precipitation compare over Australia? Adv. Meteor., 2015, 325718, https:// doi.org/10.1155/2015/325718.

Cressie, N., and H.-C. Huang, 1999: Classes of nonseparable, spatiotemporal stationary covariance functions. J. Amer. Stat. Assoc. 94, 1330-1340, https://doi.org/10.1080/01621459.1999.10473885.

Dai, A., 2006: Precipitation characteristics in eighteen coupled climate models. J. Climate, 19, 4605-4630, https://doi.org/10.1175/ JCLI3884.1.

Devine, K. A., and E. Mekis, 2008: Field accuracy of Canadian rain measurements. Atmos.-Ocean, 46, 213-227, https://doi.org/10.3137/ ao. 460202 .

Environment and Climate Change Canada, 2013: Adjusted Precipitation and Homogenized Canadian Climate Data (AHCCD). ECCC, accessed 15 January 2016, https://www.canada.ca/en/ environment-climate-change/services/climate-change/scienceresearch-data/climate-trends-variability/adjusted-homogenizedcanadian-data.html.

Eum, H.-I., A. J. Cannon, and T. Q. Murdock, 2017: Intercomparison of multiple statistical downscaling methods: Multi-criteria model selection for South Korea. Stochastic Environ. Res. Risk Assess., 31, 683-703, https://doi.org/10.1007/s00477-016-1312-9.

Gervais, M., J. Gyakum, E. Atallah, L. B. Tremblay, and R. B. Neale, 2014a: How well are the distribution and extreme values of daily precipitation over North America represented in the community climate system model? A comparison to reanalysis, satellite, and gridded station data. J. Climate, 27, 5219-5239, https://doi.org/10.1175/JCLI-D-13-00320.1.

— , L. B. Tremblay, J. R. Gyakum, and E. Atallah, 2014b: Representing extremes in a daily gridded precipitation analysis over the United States: Impacts of station density, resolution, and gridding methods. J. Climate, 27, 5201-5218, https://doi.org/10.1175/JCLI-D-13-00319.1.

Haberlandt, U., Y. Hundecha, M. Pahlow, and A. H. Schumann, 2011: Rainfall generators for application in flood studies. Flood Risk Assessment and Management: How to Specify Hydrological Loads, Their Consequences and Uncertainties, A. H. Schumann, Ed., Springer, 117-147, https://doi.org/10.1007/978-90-481-9917-4.

Hofstra, N., M. New, and C. McSweeney, 2010: The influence of interpolation and station network density on the distributions and trends of climate variables in gridded daily data. Climate Dyn., 35, 841-858, https://doi.org/10.1007/s00382-009-0698-1.

Hopkinson, R. F., D. W. McKenney, E. J. Milewska, M. F. Hutchinson, P. Papadopol, and L. A. Vincent, 2011: Impact of aligning climatological day on gridding daily maximum-minimum temperature and precipitation over Canada. J. Appl. Meteor. Climatol., 50, 1654-1665, https://doi.org/10.1175/2011JAMC2684.1.

Huffman, G. J., R. F. Adler, B. Rudolf, U. Schneider, and P. R. Keehn, 1995: Global precipitation estimates based on a technique for combining satellite-based estimates, rain gauge analysis, and NWP model precipitation information. J. Climate, $\mathbf{8}$, 1284-1295, https://doi.org/10.1175/1520-0442(1995)008<1284: GPEBOA $>2.0 . \mathrm{CO} ; 2$.

Kalnay, E., and Coauthors, 1996: The NCEP/NCAR 40-Year Reanalysis Project. Bull. Amer. Meteor. Soc., 77, 437-471, https:// doi.org/10.1175/1520-0477(1996)077<0437:TNYRP>2.0.CO;2.
Kendall, M. G., 1962: Rank Correlation Methods. 3rd ed. Charles Griffin and Co., 199 pp.

Khedhaouiria, D., A. Mailhot, and A.-C. Favre, 2018: Stochastic post-processing of CFSR daily precipitation across Canada. Atmos.-Ocean, 56, 104-116, https://doi.org/10.1080/ 07055900.2018 .1434122$.

Kleiber, W., R. W. Katz, and B. Rajagopalan, 2012: Daily spatiotemporal precipitation simulation using latent and transformed Gaussian processes. Water Resour. Res., 48, W01523, https://doi.org/10.1029/2011WR011105.

Lamb, R., D. Faulkner, P. Wass, and D. Cameron, 2016: Have applications of continuous rainfall runoff simulation realized the vision for process-based flood frequency analysis? Hydrol. Processes, 30, 2463-2481, https://doi.org/10.1002/hyp.10882.

Li, J ., M. Thyer, M. Lambert, G. Kuczera, and A. Metcalfe, 2014: An efficient causative event-based approach for deriving the annual flood frequency distribution. J. Hydrol., 510, 412-423, https://doi.org/10.1016/j.jhydrol.2013.12.035.

Lombardo, F., E. Volpi, D. Koutsoyiannis, and F. Serinaldi, 2017: A theoretically consistent stochastic cascade for temporal disaggregation of intermittent rainfall. Water Resour. Res., 53, 4586-4605, https://doi.org/10.1002/2017WR020529.

Lorente-Plazas, R., and J. P. Hacker, 2017: Observation and model bias estimation in the presence of either or both sources of error. Mon. Wea. Rev., 145, 2683-2696, https://doi.org/10.1175/ MWR-D-16-0273.1.

Lucas-Picher, P., R. Laprise, and K. Winger, 2017: Evidence of added value in North American regional climate model hindcast simulations using ever-increasing horizontal resolutions. Climate Dyn., 48, 2611-2633, https://doi.org/10.1007/ s00382-016-3227-z.

McCullag, P., and J. A. Nelder, 1989: Generalized Linear Models. 2nd ed. Chapman and Hall, 532 pp.

Mekis, E., 2005: Adjustments for trace measurements in Canada. 15th Conf. on Applied Climatology/13th Symp. on Meteorological Observations and Instrumentation, Savannah, GA, Amer. Meteor. Soc., J3.7, https://ams.confex.com/ams/ 15AppClimate/techprogram/paper_92155.htm.

_ ation adjusted daily precipitation dataset for trend analysis in Canada. Atmos.-Ocean, 49, 163-177, https://doi.org/10.1080/ 07055900.2011.583910.

Mesinger, F., and Coauthors, 2006: North American Regional Reanalysis. Bull. Amer. Meteor. Soc., 87, 343-360, https:// doi.org/10.1175/BAMS-87-3-343.

Naveau, P., R. Huser, P. Ribereau, and A. Hannart, 2016: Modeling jointly low, moderate, and heavy rainfall intensities without a threshold selection. Water Resour. Res., 52, 2753-2769, https://doi.org/10.1002/2015WR018552.

Neykov, N. M., P. N. Neytchev, and W. Zucchini, 2014: Stochastic daily precipitation model with a heavy-tailed component. Nat. Hazards Earth Syst. Sci., 14, 2321-2335, https://doi.org/10.5194/ nhess-14-2321-2014.

Onof, C., R. E. Chandler, A. Kakou, P. Northrop, H. S. Wheater, and V. Isham, 2000: Rainfall modelling using Poisson-cluster processes: A review of developments. Stochastic Environ. Res. Risk Assess., 14, 384-411, https://doi.org/10.1007/ s004770000043.

Pegram, G., and A. Clothier, 2001: High resolution space-time modeling of rainfall: The "string of beads" model. J. Hydrol., 241, 26-41, https://doi.org/10.1016/S0022-1694(00)00373-5.

Peterson, T. C., C. Folland, G. Gruza, W. Hogg, A. Mokssit, and N. Plummer, 2001: Report on the activities of the Working 
Group on Climate Change Detection and related rapporteurs 1998-2001. WMO Tech. Rep., 143 pp., http://etccdi. pacificclimate.org/docs/wgccd.2001.pdf.

Plummer, D. A., and Coauthors, 2006: Climate and climate change over North America as simulated by the Canadian RCM. J. Climate, 19, 3112-3132, https://doi.org/10.1175/JCLI3769.1.

Podgórski, K., and J. Wegener, 2012: Velocities of a spatialtemporal stochastic field with embedded dynamics. Environmetrics, 23, 238-252, https://doi.org/10.1002/env.2135.

Saha, S., and Coauthors, 2010: The NCEP Climate Forecast System Reanalysis. Bull. Amer. Meteor. Soc., 91, 1015-1057, https://doi.org/10.1175/2010BAMS3001.1.

Schlather, M., and Coauthors, 2017: RandomFields: Simulation and analysis of random fields: $\mathrm{R}$ package version 3.1.50. Comprehensive R Archive Network, 374 pp., https://cran. r-project.org/web/packages/RandomFields/RandomFields.pdf.

Schmidli, J., C. Frei, and P. L. Vidale, 2006: Downscaling from GCM precipitation: A benchmark for dynamical and statistical downscaling methods. Int. J. Climatol., 26, 679-689, https:// doi.org/10.1002/joc.1287.

Serinaldi, F., and C. G. Kilsby, 2014: Simulating daily rainfall fields over large areas for collective risk estimation. J. Hydrol., 512, 285-302, https://doi.org/10.1016/j.jhydrol.2014.02.043.

Stein, M. L., 1999: Interpolation of Spatial Data: Some Theory for Kriging. Springer-Verlag, 249 pp.

Stern, R. D., and R. Coe, 1984: A model fitting analysis of daily rainfall data. J. Roy. Stat. Soc., 147A, 1-34, https://doi.org/ 10.2307/2981736.

Sun, X., A. P. Barros, X. Sun, and A. P. Barros, 2010: An evaluation of the statistics of rainfall extremes in rain gauge observations, satellite-based and reanalysis products using universal multifractals. J. Hydrometeor., 11, 388-404, https://doi.org/10.1175/ 2009JHM1142.1.
Sun, Y., S. Solomon, A. Dai, and R. W. Portmann, 2006: How often does it rain? J. Climate, 19, 916-934, https://doi.org/10.1175/ JCLI3672.1.

Vaittinada Ayar, P., M. Vrac, S. Bastin, J. Carreau, M. Déqué, and C. Gallardo, 2016: Intercomparison of statistical and dynamical downscaling models under the EURO- and MED-CORDEX initiative framework: Present climate evaluations. Climate Dyn., 46, 1301-1329, https://doi.org/10.1007/s00382-015-2647-5.

Vrac, M., and P. Naveau, 2007: Stochastic downscaling of precipitation: From dry events to heavy rainfalls. Water Resour. Res., 43, W07402, https://doi.org/10.1029/2006WR005308.

Way, R. G., F. Oliva, and A. E. Viau, 2017: Underestimated warming of northern Canada in the Berkeley Earth temperature product. Int. J. Climatol., 37, 1746-1757, https://doi.org/ $10.1002 /$ joc. 4808 .

Wheater, H. S., and Coauthors, 2005: Spatial-temporal rainfall modelling for flood risk estimation. Stochastic Environ. Res. Risk Assess., 19, 403-416, https://doi.org/10.1007/s00477-0050011-8.

Wijngaard, J. B., A. M. G. Klein Tank, and G. P. Können, 2003: Homogeneity of 20th century European daily temperature and precipitation series. Int. J. Climatol., 23, 679-692, https:// doi.org/10.1002/joc.906.

Wong, G., D. Maraun, M. Vrac, M. Widmann, J. M. Eden, and T. Kent, 2014: Stochastic model output statistics for bias correcting and downscaling precipitation including extremes. J. Climate, 27, 6940-6959, https://doi.org/10.1175/JCLI-D-1300604.1.

Yee, T. W., 2016: VGAM: Vector generalized linear and additive models: R package version 1.0-3. Comprehensive R Archive Network, http://CRAN.R-project.org/package=VGAM.

— , and C. J. Wild, 1996: Vector generalized additive models. J. Roy. Stat. Soc., 58B, 481-493. 